Check for updates

Cite this: RSC Adv., 2018, 8, 40511

Accepted 21st November 2018

DOI: $10.1039 / \mathrm{c} 8 \mathrm{ra} 07221 \mathrm{c}$

rsc.li/rsc-advances
Received 29th August 2018

\section{Regression, kinetics and isotherm models for biosorption of organic pollutants, suspended and dissolved solids by environmentally friendly and economical dried Phragmites australis $\dagger$}

\begin{abstract}
Abeer El Shahawy (iD) *a and Ghada Heikal (DD ${ }^{\text {b }}$
Low cost adsorbents such as $P$. australis have received considerable interest owing to their low cost and easy availability. The aim of the present study was the evaluation of the removal of chemical oxygen demand (COD), biological oxygen demand (BOD), total suspended and dissolved solids (TSS and TDS) using dried $P$. australis in influent wastewater to a wastewater treatment plant. The results of the COD and $\mathrm{BOD}$ concentration reduction with $P$. australis at optimum operating conditions were determined for maximum reduction and adsorption isotherms. The maximum reduction of COD, BOD, TSS and TDS concentrations under the optimum operating conditions was 92.27\%, 93.89\%, 94.38\% and 91.61\%, respectively. The results demonstrate that the new dried biosorbent is able to adsorb all the aforementioned contamination. It achieved an adsorption capacity for COD of $72.5 \mathrm{mg} \mathrm{g}^{-1}$ and an adsorption capacity for BOD of $43.93 \mathrm{mg} \mathrm{g}^{-1}$. The results were well fitted by the pseudo-second order model with $R^{2}=0.984$
\end{abstract}

\section{Introduction}

Owing to the fast depletion of freshwater resources, the world is facing a fresh water crisis. Industrial and domestic activities have polluted the surface water as well as ground water to a greater extent. ${ }^{1}$ It is therefore important that a supply of good quality water should be available for various activities. However, this is becoming gradually more difficult in view of the major pollution caused by industrial, agricultural and domestic activities. These activities produce wastewater with both inorganic and organic pollutants, which result in water pollution. ${ }^{2}$ In rural, urbanized villages and small towns in most developing and poor countries, sewage is discharged in open drain branches. Wastewater treatment services do not exist in these areas. Wastewater collects in low lying areas or flows to open water ponds, creating a dangerous source of health threat. The conventional wastewater treatment systems are not suited for the reorganized uses for these residents. There is a critical need to develop simple, inexpensive methods and cheap strategies to treat sewage from villages, towns and cities in developing and poor countries. Chemical oxygen demand (COD), biochemical oxygen demand (BOD) and total organic carbon are measured

${ }^{a}$ Department of Civil Engineering, Faculty of Engineering, Suez Canal University, PO Box 41522, Ismailia, Egypt. E-mail: ahmedabeer12000@yahoo.com

${ }^{b}$ Environmental Engineering Department, Faculty of Engineering, Zagazig University, 44519, Egypt. E-mail: reemhatem2006@hotmail.com; Tel: +201224441973

$\dagger$ Electronic supplementary information (ESI) available. See DOI: $10.1039 / \mathrm{c} 8 \mathrm{ra} 07221 \mathrm{c}$ as organic pollutants of wastewater. ${ }^{3}$ Wastewater treatment includes treatments such as physical, chemical and biological for removal of different pollutants from wastewater. The physical removal treatments includes screening and bar racks. The secondary treatments include biological treatments, such as activated sludge and trickling filters. Methods for organic matter removal, including various biological and non-biological methods, such as adsorption and membrane separation, can be used efficiently for removal of organic matter and heavy metals. ${ }^{4}$ Among these accessible procedures, adsorption is the most appealing choice for its simple application and high cost viability. Biosorption is an innovative and cost-effective biotechnology for the treatment of high-volume and lowconcentration complex wastewaters and it has some advantages over some other methods for contamination removal, including high adsorption capacity and flexible operation. ${ }^{5-7}$

Lignocellulosic biomass derived from agricultural byproducts has proven to be a promising type of raw material for producing activated carbon (AC) owing to its abundance, renewability, and rich carbon content. ${ }^{8}$ Stalk or stem biomass is a rich source for activated carbon production with high surface area and adsorption performance compared to that from other biomass, such as leaves or roots, owing to its high volume, low ash, high carbon, and reasonable hardness. ${ }^{9}$ Corn stalks, ${ }^{10}$ grape stalks, ${ }^{11}$ lotus stalks, ${ }^{12}$ cotton stalks, ${ }^{13}$ banana stalks, ${ }^{14}$ tobacco stems, ${ }^{15}$ palm stems, ${ }^{16}$ and giant reed stems ${ }^{17,18}$ have been utilized as efficient precursors for ACs with well-developed porous structures. 
AC is commonly used for organic and contaminant adsorption. The majority of the past research has focused on synthetic feed models made from specific organic materials. For instance, waste materials and byproducts from agriculture and industry have been broadly used for wastewater treatment, such as biogas residues, chitosan, Saccharomyces cerevisiae and biomass. The vast majority of these materials are nanomaterials, which have extensive surface regions, simple change, and expansive number of dynamic destinations for overwhelming metal evacuation. However, these materials still suffer from drawbacks, such as complex preparation process, as well as difficulty in separation and regeneration. ${ }^{19}$ Recently, natural materials have attracted increasing attention as adsorbents for heavy metals because of their renewable and biodegradable properties, such as walnut shells, coir pith, apricot stones, almond shells, hazelnut shells, silk cotton hulls, maize cobs, coconut coir dust, peach stones, and sugarcane bagasse. ${ }^{20}$

Phragmites australis (reed) is an extensive perpetual grass found in wetlands all through calm and tropical locales of the world. $P$. australis is a warm season plant and it is well-known to have wide climatic tolerance. It can mature up to $6 \mathrm{~m} \mathrm{high}$, is seemingly perpetual and contains high levels of lignin and cellulose. The properties of $P$. australis not only give a possibly economical material for wastewater treatment, yet in addition help surface adjustment by methods for gathering extraordinary quantities of hydroxyl $(\mathrm{OH})$ on its surface. Hence, P. australis has been utilized for quite a long time for the removal of a vast array of metals and metalloids from amphibian frameworks and wastewater. ${ }^{21} P$. australis is a very promising biosorbent because of its dense growth and its spreading root system. In addition, it has the ability to resist hostile environmental surroundings, such as alternating wet and dry conditions, elevated $\mathrm{CO}_{2}$ levels and high temperature. For all the previous reasons, $P$. australis is considered as one of the most effective water clearing plants for the tropics. P. australis has played a vital role in land reclamation. ${ }^{22,23}$ Although, there are different advantages of Phragmites australis, nearly no available studies exist in COD, BOD, TSS and TDS removal.

The best harvesting conditions can take place in the seed maturation stage and when the fine leaves become dry. To reduce insect and fungal attacks, moisture content should be eliminated as much as possible. To take benefit of the most durable part of the stem, it should be cut as close to the ground as possible. The stems with cut ends aligned are loosely tied in small bundles and combed to remove debris and fine leaves. Usually, an area is selected and all $P$. australis within that area is harvested. The cut reeds are sorted into bundles containing stems of even thickness and length. The taller and thicker stems are the most prized and of the highest quality. $P$. australis needs 1.6-2.0 hectares to cover $140 \mathrm{~m}^{2}$. Handling after harvest is vital. Freshly cut stems, complete with leaves, are tied into bundles and left to stand for a few days, allowing the leaves to transpire and reduce the starch content of the stem. This method, called "clump curing", reduces attack by borer beetles, but has no effect on termites or fungi. Efficient resistance to termites, most types of fungus and fire is attained principally by chemical treatment. Dry, well-ventilated storage is essential. ${ }^{24}$ Reeds are one of the most frequent and dominant species in wetlands all over the world. In some cases, reed cutting can remove the $\mathrm{N}$ and $\mathrm{P}$ from the wetland, which accelerates eutrophication by pumping up nutrients from the sediments. ${ }^{25}$

This research mainly focused on the removal of organic pollutants from wastewater influent directly to wastewater treatment plants. The objective of the present work was to investigate the effectiveness of Phragmites australis as a biosorbent for the removal of COD, BOD, TSS and TDS from domestic wastewater. The focal goals of this study are to:

(i) Characterize the synthesized biosorbent by scanning electron microscopy (SEM) and Fourier transform infrared spectroscopy (FTIR).

(ii) Systematically evaluate the influences of various experimental parameters, such as biosorbent dose, contact time, $\mathrm{pH}$, agitation speed and initial COD, BOD, TSS and TDS concentrations on adsorption performance.

(iii) Reveal the mechanisms of COD, BOD, TSS and TDS adsorption onto dried Phragmites australis biomass by determination of COD, BOD, TSS and TDS sorption kinetics, characterize COD, BOD, TSS and TDS sorption isotherms and compare sorption properties to those of other adsorbent materials. The study represents a milestone in the use of dried Phragmites australis biomass for future applications.

\section{Materials and methods}

\subsection{Collection and composition of wastewater}

Wastewater samples were taken from EL Keanayat wastewater treatment plant, Zagazig City, Sharkiah, Egypt after primary treatment. Wastewater can have a major adverse impact on water quality in terms of biological oxygen demand (BOD), chemical oxygen demand (COD), total suspended solids (TSS), and total dissolved solids (TDS). Table 1 displays the maximum allowable effluent discharge standards for $\mathrm{pH}$, COD, BOD, TDS, and TSS (according to the Egyptian law 48/1982 for irrigation water). Additionally, the table summarizes the main characteristics of the wastewater parameters as average values, i.e. average measurements for readings through a year. All analyses were conducted according to the standard methods for the examination of water and wastewater. Chemical oxygen demand (COD) was measured by the closed reflux colorimetric method. Biochemical oxygen demand (BOD) was measured by the 5 days test method (see ESI $S_{1} \dagger$ ). Total suspended solids (TSS) were measured after filtration and drying at $103-105{ }^{\circ} \mathrm{C}$. Settleable solids were measured by the gravimetric method. Total dissolved solids (TDS) were measured from the filtered liquid by the gravimetric method. The $\mathrm{pH}$ of aqueous solution was adjusted to $4-9$ by addition of $\mathrm{NaOH}(0.1 \mathrm{M})$ or $\mathrm{HCl}(0.1 \mathrm{M})$.

\subsection{Biosorbent preparation and its characterization}

Phragmites australis (reeds) were collected from El Agoa canal in Zagazig town, situated in the Nile Delta region of Egypt. The gathered plants were analyzed, washed with $1 \% \mathrm{HCl}$, and after that flushed with deionized water to remove dust, residual HCL and resins attached on the plant parts. After that, the plants 
Table 1 The characteristics of the studied wastewater parameters

\begin{tabular}{lll}
\hline Parameter & Average value & $\begin{array}{l}\text { Maximum }^{\text {allowable }}{ }^{a} \\
\text { pH }\end{array}$ \\
BOD (ppm) & $6.8-7$ & $6-9$ \\
COD (ppm) & $645-655$ & 40 \\
TSS (ppm) & $1000-1100$ & 80 \\
TDS (ppm) & $442-445$ & 50 \\
& $828-834$ & 2000
\end{tabular}

${ }^{a}$ Egyptian code of Environmental Regulations (1982): (4/1994).

were placed in an oven (Shimaden) at $70{ }^{\circ} \mathrm{C}$ for $48 \mathrm{~h}$ to reach an oven-dry weight. Plant samples were finely crushed, grinded, and then sieved to give the desired particle size. Phragmites australis is $\mathrm{a}_{3} \mathrm{C}_{3}$ plant, but has anatomical characteristics intermediate between $\mathrm{C}_{3}$ and $\mathrm{C}_{4}$ plants. Raw Phragmites australis contains, per $100 \mathrm{~g}$ dried biomass, about $39.5 \mathrm{~g}$ and $42.7 \mathrm{~g}$ of cellulose, $29.69 \mathrm{~g}$ and $27.27 \mathrm{~g}$ of lignin, and $23.61 \mathrm{~g}$ and $23.73 \mathrm{~g}$ of hemicellulose in the leaves and stems, respectively. The basic composition of the lignocellulosic materials is summarized in Table 2. Each experiment (refer to ESI $\mathrm{S}_{2} \dagger$ for the methods used for compositional analysis) was carried out in triplicate and the reported results indicate the average values of the replicated experiments. The results from the compositional analysis of raw lignocelluloses of raw Phragmites australis biomass $(\% \mathrm{w} / \mathrm{w})$ are shown in Table 2.

\subsection{Instruments}

The $\mathrm{pH}$ was determined by using a $\mathrm{pH}$ meter (AD1000). All the chemicals used in the study were analytically pure and were purchased from local suppliers in Egypt. Stainless-steel sieves (Standard Sieves Dual Manufacturing Co., USA) were used to obtain the biosorbent with a definite particle size. All physicochemical analyses were performed according to the standard methods for examination of water and wastewater (APHA, 1998). The surface of the studied biosorbent, before and after the biosorption process, was analyzed and photographed using a scanning electron microscope (JEOL JSM-6510LV SEM, USA) equipped with energy dispersive X-ray spectroscopy (EDX). A Fourier transform infrared (FT-IR) spectrometer (JASCO 4100, USA) was used to detect the main functional groups responsible for organic load biosorption. The spectra were collected using an FT-IR instrument equipped with a diffuse reflectance accessory within the wavenumber range of $400-4000 \mathrm{~cm}^{-1}$.

\subsection{Batch biosorption procedure}

The first part of this study aimed at determining the optimum operating parameters for organic load biosorption. This included the effects of $\mathrm{pH}$ (4 to 9), biomass dosage level (0.5 to $3.5 \mathrm{~g} \mathrm{~L}^{-1}$ ), contact time (10 to $180 \mathrm{~min}$ ) and agitation speed (120-300 rpm) with a plant particle size $<0.15 \mathrm{~mm}$ on organic load removal and uptake capacity. All experiments were conducted in triplicate at a constant room temperature of $25 \pm 3{ }^{\circ} \mathrm{C}$ using jar test (IMASS) apparatus for every kinetic experiment with $250 \mathrm{~mL}$ of domestic wastewater. The second part of this study was used to determine the effect of the initial COD, BOD, TSS and TDS concentrations by dried $P$. australis biomass. COD, BOD, TSS and TDS concentrations were varied ranging from $200 \mathrm{mg} \mathrm{L}^{-1}$ to $1100 \mathrm{mg} \mathrm{L}^{-1}$, from $100 \mathrm{mg} \mathrm{L}^{-1}$ to $655 \mathrm{mg} \mathrm{L}^{-1}$, from $89 \mathrm{mg} \mathrm{L}^{-1}$ to $445 \mathrm{mg} \mathrm{L}^{-1}$ and from $166 \mathrm{mg} \mathrm{L}^{-1}$ to $834 \mathrm{mg} \mathrm{L}^{-1}$, respectively, at the optimum adsorbent dose, contact time, $\mathrm{pH}$ and agitation speed identified from the first part.

\subsection{Biosorption isotherm models}

Adsorption isotherms are harmony conditions that regularly express the measure of the adsorbate on the adsorbent as a component of its concentration. The linear form of the Langmuir isotherm refers to the Langmuir equation. ${ }^{26}$ The logarithmic form of the Freundlich model refers to the Freundlich equation ${ }^{27}$ (see ESI $\mathrm{S}_{3} \dagger$ ).

\subsection{Kinetic studies}

The adsorption rates of COD, BOD, TSS, and TDS were studied at different time intervals (10-180) min using initial concentrations of $1100,655,445$ and $834 \mathrm{mg} \mathrm{L}^{-1}$, respectively, at the optimum adsorbent dose, $\mathrm{pH}$ and agitation speed. The modeling of the adsorption kinetics of COD, BOD, TSS and TDS for $P$. australis were checked by two common models, pseudofirst-order and pseudo-second-order. ${ }^{28}$ The details of the equations are summarized in $\mathrm{S}_{3}$ (see ESI $\mathrm{S}_{3} \dagger$ ).

2.6.1 The pseudo-first-order kinetic model. The pseudofirst-order model can be expressed by eqn $\left(1-\mathrm{S}_{3}\right)$. The values of $\log \left(q_{\mathrm{e}}-q_{t}\right)$ were calculated from the kinetic data and plotted against time, $t$. A linear fit to the experimental data gives a straight line with a slope $k_{1} / 2.303$ and an intercept of $\log \left(q_{\mathrm{e}}\right)(1)$.

$$
\log \left(q_{\mathrm{e}}-q_{t}\right)=\log \left(q_{\mathrm{e}}\right)-\frac{K_{1}}{2.303} t
$$

where, $q_{t}$ is the amount of COD, BOD, TDS \& TSS adsorbed at time $t\left(\mathrm{mg} \mathrm{g}^{-1}\right) ; k_{1}$ is the rate constant of pseudo-first-order in $\mathrm{mg} \mathrm{g}^{-1} \mathrm{~min}^{-1}$.

Table 2 Compositional analysis of raw lignocelluloses from raw Phragmites australis biomass (\%w/w) ${ }^{a}$

\begin{tabular}{|c|c|c|c|c|c|}
\hline Proximate analysis (wt\%) & Leaves & Stems & Lignocellulosic composition (wt\%) & Leaves & Stems \\
\hline Ash & $4.50 \pm 0.02$ & $5.10 \pm 0.026$ & Cellulose & $39.50 \pm 1.75$ & $42.70 \pm 1.83$ \\
\hline Moisture & $3.70 \pm 0.15$ & $4.20 \pm 0.11$ & Lignin & $29.69 \pm 3.15$ & $27.27 \pm 2.38$ \\
\hline Fixed carbon & $49.80 \pm 0.36$ & $54.60 \pm 0.32$ & Extractives & $7.20 \pm 0.74$ & $6.30 \pm 0.89$ \\
\hline
\end{tabular}

${ }^{a}$ All values are the mean \pm SD mean for three replicates. 


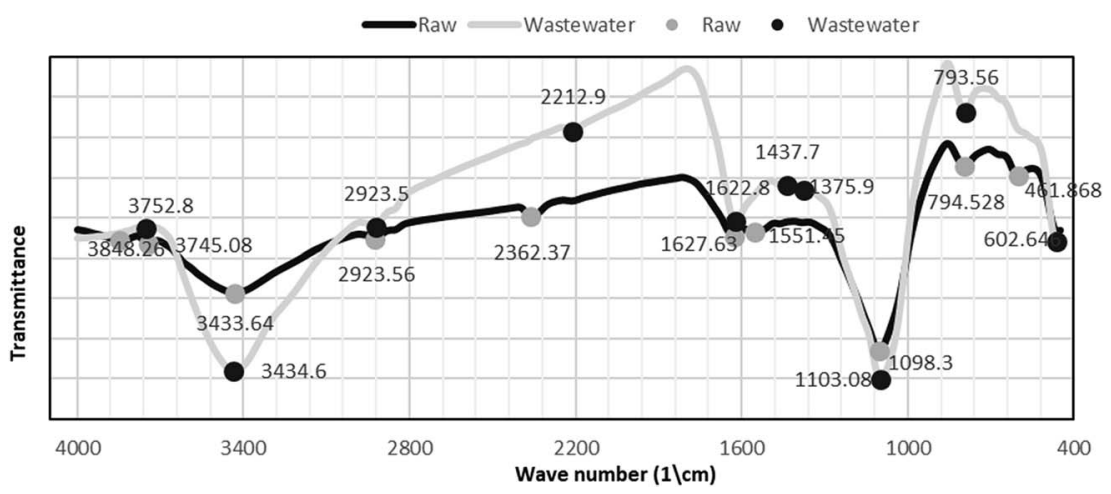

Fig. 1 FTIR spectrum of Phragmites australis dried biomass before and after biosorption.

2.6.2 The pseudo-second-order model. The pseudo-secondorder model can be expressed by eqn $\left(2-\mathrm{S}_{3}\right)$. The values of $t / q_{t}$ were calculated from the kinetic data and plotted against time, $t$. A linear fit to the experimental data should give a straight line with a slope $1 / q_{\mathrm{e}}$ and an intercept $1 /\left(k_{2} q_{\mathrm{e}}^{2}\right)(2)$.

$$
\frac{t}{q_{t}}=\frac{1}{K_{2} q_{\mathrm{e}}^{2}}+\frac{t}{q_{\mathrm{e}}}
$$

where $k_{2}$ is the pseudo-second-order rate constant in $g$ $\mathrm{mg}^{-1} \min ^{-1}$.

\subsection{Statistical analysis}

Single analysis of variance (ANOVA) and simple correlation analysis were applied to the numerical data in this study. Oneway ANOVA (at a significance level of 0.05) was applied to assess the removal efficiencies of the biosorption capacity.
Interactive response surface methodology (IRSM) is a combination of statistical techniques used for designing experiments, generating models, and estimating the effects of variables. IRSM generates simulated data at combinations of independent variables specified by a designed experiment. ${ }^{29}$ IRSM was based on a pure-quadratic regression model, eqn (1), to fit the experimental results.

$$
\begin{aligned}
Y= & \beta_{0}+\beta_{1} x_{1}+\beta_{2} x_{2}+\beta_{3} x_{3}+\beta_{4} x_{4}+\beta_{5} x_{5}+\beta_{6} x_{1}^{2}+\beta_{7} x_{2}^{2} \\
& +\beta_{8} x_{3}^{2}+\beta_{9} x_{4}^{2}+\beta_{10} x_{5}^{2}
\end{aligned}
$$

where $Y$ is the predicted response of BOD, COD, TSS and TDS removal efficiency (\%); $x_{1}$ is $\mathrm{pH}(4-9) ; x_{2}$ is initial COD, BOD, TSS and TDS concentration (200-1100, 100-655, 89-445 and $166-834 \mathrm{mg} \mathrm{L}^{-1}$, respectively); $x_{3}$ is contact time (10-180 $\left.\mathrm{min}\right)$; $x_{4}$ is agitation speed (120-300 rpm); $x_{5}$ is biomass dosage (0.5$3.5 \mathrm{~g}) ; \beta_{0}$ is the model intercept; $\beta_{1}, \beta_{2}, \beta_{3}, \beta_{4}$, and $\beta_{5}$ are the

Table 3 Surface functional groups observed on Phragmites australis before and after COD, BOD, TSS and TDS biosorption using FTIR

Band position $\left(\mathrm{cm}^{-1}\right)$

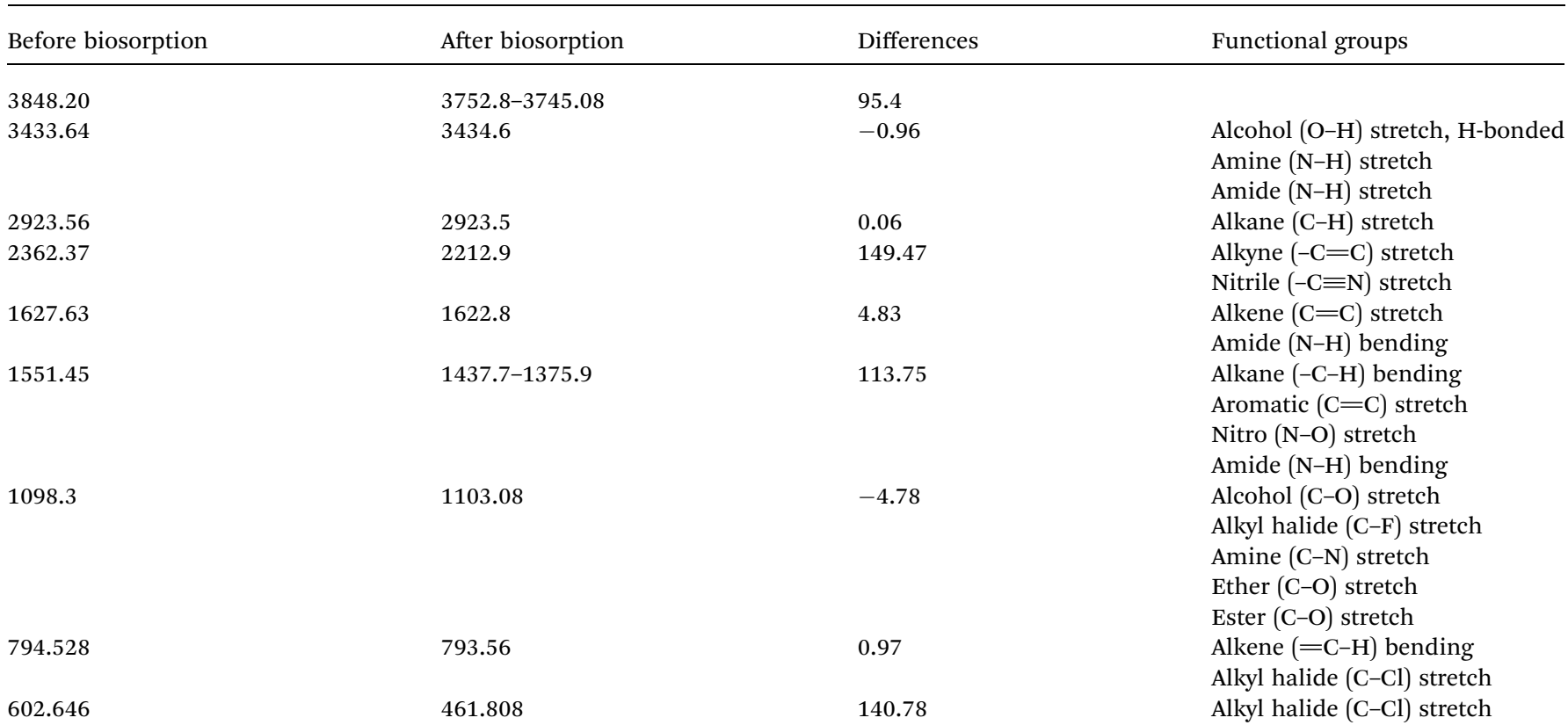




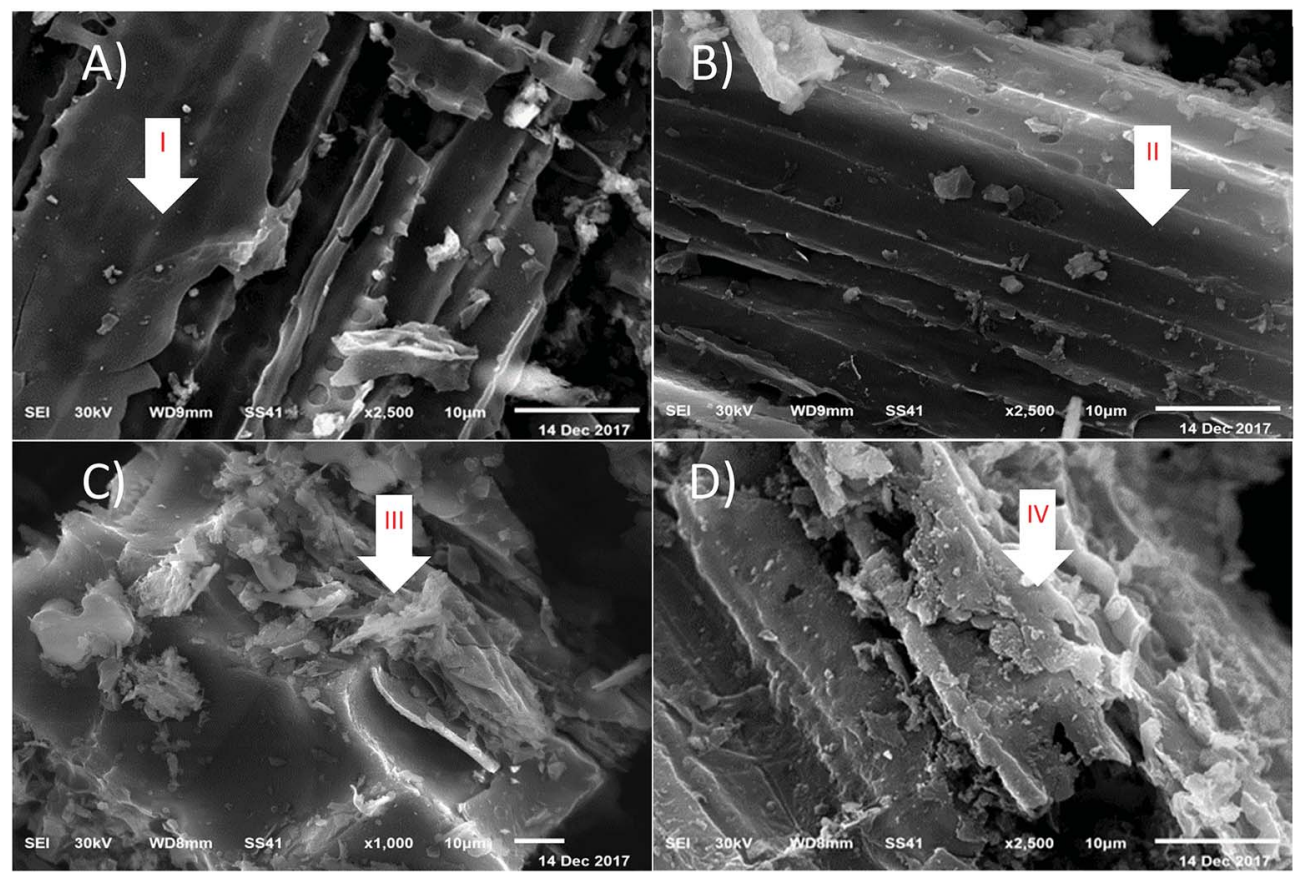

Fig. 2 (A) and (B) SEM micrographs of raw dried $P$. australis biomass at magnification power of $2500 \times$. (C) and (D) SEM micrographs of dried $P$. australis biomass after adsorption at magnification power of $1000 \times$ and $2500 \times$, respectively.

linear coefficients of $x_{1}, x_{2}, x_{3}, x_{4}$ and $x_{5}$, respectively; and $\beta_{6}, \beta_{7}$, $\beta_{8}, \beta_{9}$, and $\beta_{10}$ are the quadratic coefficients of $x_{1}, x_{2}, x_{3}, x_{4}$ and $x_{5}$, respectively.

\section{Results and discussion}

\subsection{Characterization of raw and polluted $P$. australis dried} biomass

3.1.1 FTIR spectroscopy. Fig. 1 shows the FTIR spectrum of Phragmites australis dried biomass before and after biosorption. The FTIR spectra of both the raw and adsorbent (loaded) plant biomass show that the band at $3434.6 \mathrm{~cm}^{-1}$ displays the distinguished broad $-\mathrm{OH}$ alcoholic groups of the cellulose and lignin structure.

Surface functional groups observed on Phragmites australis before and after COD, BOD, TSS and TDS biosorption using FTIR are illustrated in Table 3 . In addition, it shows a band at $2923.5 \mathrm{~cm}^{-1}$ assigned to the $\mathrm{CH}$ stretching of methyl and methylene groups. Bands at 1627.8, $1551.45 \mathrm{~cm}^{-1}$ are assigned for $\mathrm{C}=\mathrm{C}$ alkene and aromatics, respectively. The band at $1437.7 \mathrm{~cm}^{-1}$ is attributed to the $\mathrm{CH}_{2}$ of cellulose, hemicellulose and lignin. The band at $1375.9 \mathrm{~cm}^{-1}$ is for the ether group C-O.

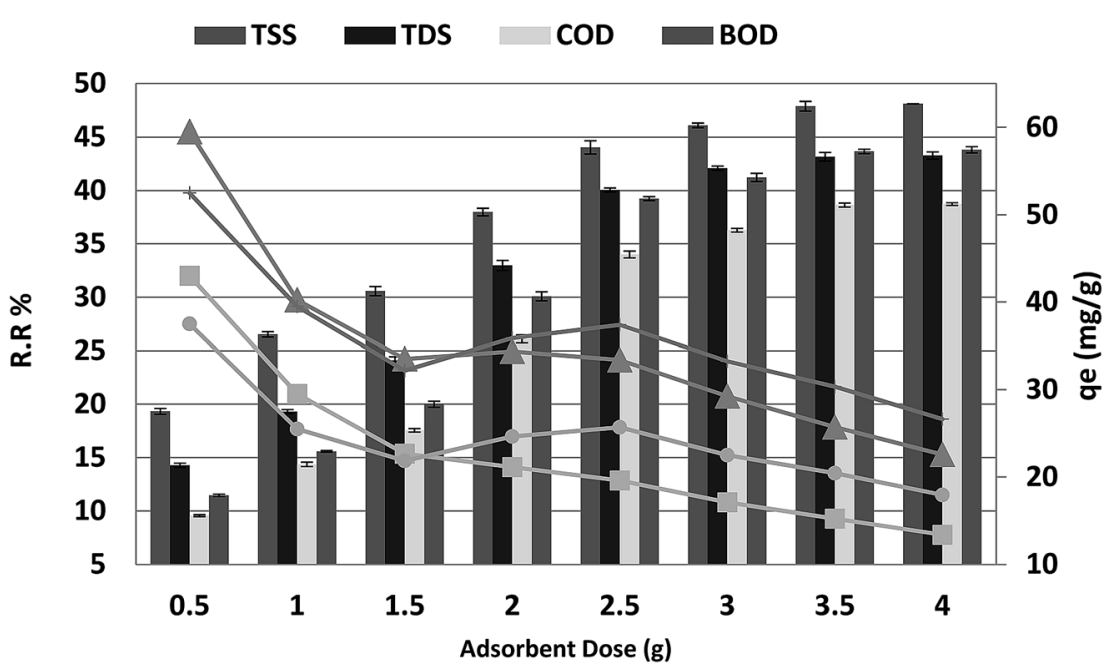

Fig. 3 Effect of absorbent dose on the removal of efficiency and adsorption capacity for BOD, COD, TSS and TDS with a contact time of 20 min at $\mathrm{pH} 4$ and agitation speed of $150 \mathrm{rpm}$. 


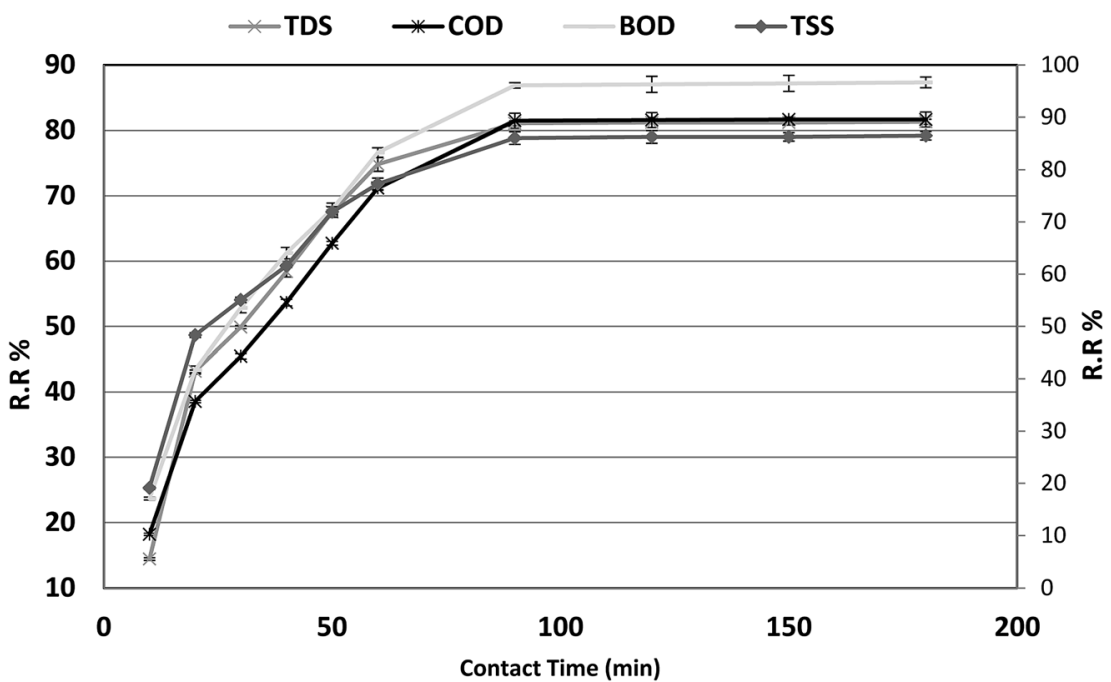

Fig. 4 Effect of contact time on the removal of efficiency of BOD, COD, TSS and TDS at an absorbent dose of $3.5 \mathrm{~g}$. pH 4 , and agitation speed of $150 \mathrm{rpm}$.

The strong band at $1098 \mathrm{~cm}^{-1}$ is assigned to $\mathrm{O}-\mathrm{H}$ bending vibration. Bending of $\mathrm{C}=\mathrm{C}$ bonds appeared at $793.5 \mathrm{~cm}^{-1}$. The results reveal that a large amount of chemical functional groups were preserved and generated on the surface of $P$. australis, which might enhance its adsorptive properties.

3.1.2 Scanning electron microscopy (SEM) studies. The overall morphology and microscopic porous structure of the samples can be clearly seen from the SEM images, as illustrated in Fig. 2A-D. In this study, SEM photomicrographs of P. australis at a magnification power of $2500 \times$ showed the morphology of $P$. australis raw dried powder, as shown in Fig. 2A and B. SEM photomicrographs of the organic load and $P$. australis at magnification power $2500 \times$ and $1000 \times$ showed the morphological changes to $P$. australis after biosorption, as shown in Fig. 2C and D. The SEM micrographs of the raw dried powder of $P$. australis show irregular particles in the range of few micrometers to few hundred micrometers. The surface of the raw dried biomass is fluffy and rough, showing a regular and compact surface structure with fibers arranged in bundles. The enhanced pictures exhibit big squares that contain channels, and the dividers of channels contain numerous bigger pores, as pointed to by arrows I and II. It can also be observed in Fig. $2 \mathrm{~A}$ and $\mathrm{B}$ that the surface of the raw dried biomass is cleaner than the surface of the dried biomass after adsorption

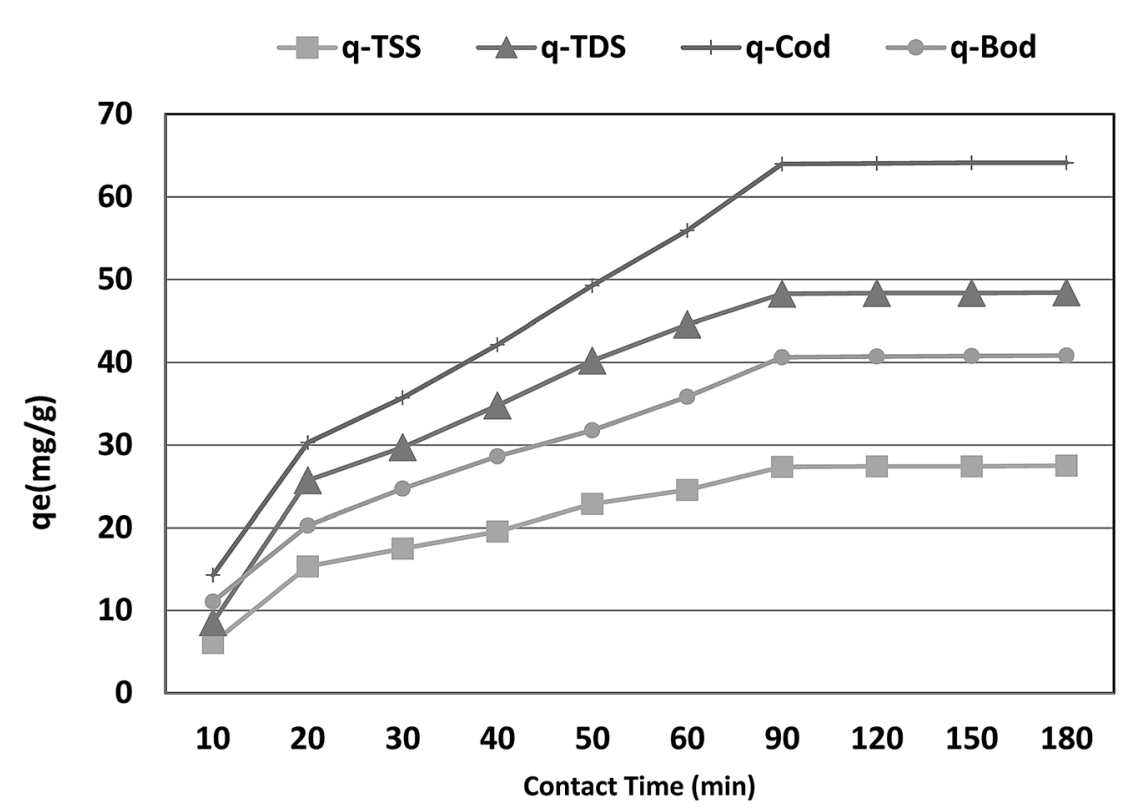

Fig. 5 Effect of contact time on the adsorption capacity of BOD, COD, TSS and TDS at an absorbent dose of $3.5 \mathrm{~g}$. pH 4, and agitation speed of $150 \mathrm{rpm}$. 
Table 4 Parameters of the reaction kinetics (pseudo-first-order, pseudo-second-order) for COD, BOD, TSS and TDS biosorption using Phragmites australis (at room temperature of $25.00 \pm 3.00^{\circ} \mathrm{C}$ )

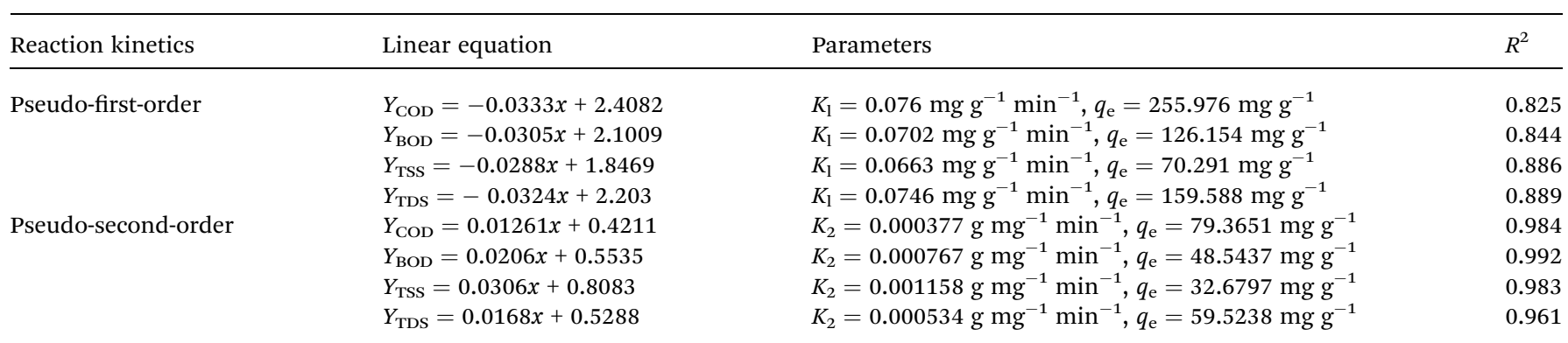

of the organic loads of COD, BOD, TSS and TDS. The surface morphology of the dried $P$. australis biomass varied and organic load molecules accumulated on the biomass surface, indicating that the organic load adsorption had occurred at the surface, as pointed to by arrows III and IV. As presented in Fig. 2C and D, the organic load particles formed aggregates of various shapes and sizes. After adsorption of COD, BOD, TSS and TDS, the pores ended up undetectable in light of the fact that the exterior biomass surface had been covered by the organic load. SEM analysis demonstrated the high affinity of $P$. australis for the immediate natural burdens, confirming the adsorption procedure.

\subsection{Biosorbent dose}

The effect of adsorbent dosage on the percentage COD, BOD, TSS and TDS removal from $250 \mathrm{~mL}$ of wastewater after $20 \mathrm{~min}$ is shown in Fig. 3. The percentage removal of COD, BOD, TSS and TDS increased as the $P$. australis dosage increased and reached equilibrium at a dosage of $3.5 \mathrm{~g}$. The increase in the adsorption of the COD, BOD, TSS and TDS by P. australis may be ascribed to availability of more binding sites and the high surface area. After the addition of $3.5 \mathrm{~g}$, the percentage removal of COD, BOD, TSS and TDS increased rapidly from $9.55 \%$ to $38.64 \%, 11.45 \%$ to $43.66 \%, 19.33 \%$ to $47.87 \%$ and $14.47 \%$ to $43.17 \%$, respectively, with the amount of added $P$. australis increasing from 0.5 to $3.5 \mathrm{~g}$ per $250 \mathrm{~mL}(r 0.984, p 0.000),(r 0.980, p 0.000),(r 0.981, p$
$0.000)$, and $(0.978,0.000)$ for COD, BOD, TSS and TDS, respectively. There was no significant change in the COD, BOD, TSS and TDS removal with increases in the adsorbent dose above $3.5 \mathrm{~g}$, i.e. the percentage removal of COD, BOD, TSS and TDS was $38.73 \% \pm 0.13,43.82 \% \pm 0.29,48.09 \% \pm 0.01$, and $43.29 \%$ \pm 0.34 , respectively, with the added amount of $P$. australis at $4.0 \mathrm{~g}$ per $250 \mathrm{~mL}$. This may be linked to the aggregation of binding sites and perhaps a decrease in the total adsorbent surface area of particles available to COD, BOD, TSS and TDS. Additionally, an increase in the biosorbent dose from 2 to $14.0 \mathrm{~g}$ $\mathrm{L}^{-1}$ negatively affected the $P$. australis capacity $\left(q_{\mathrm{e}}\right)(r-0.768, p$ 0.044), $(r-0.726, p 0.065),(r-0.900, p 0.006)$, and ( $\mathrm{r}-0.861, p$ $0.013)$ for COD, BOD, TSS and TDS respectively. The P. australis capacity is mg of pollutant adsorbed per gram of Phragmites australis biomass and is calculated according to the following equation:

$$
q_{\mathrm{e}}=\left(C_{0}-C_{\mathrm{e}}\right) \times V / m
$$

where $V$ is solution volume in liters, and $m$ is the biomass weight in grams. The lowest values of $30.36,20.43,15.21$ and $25.71 \mathrm{mg} \mathrm{g}^{-1}$ were recorded at $14.0 \mathrm{~g} \mathrm{~L}^{-1}$ for COD, BOD, TSS and TDS, respectively. The relationship between uptake and dosage appears to be in contrast to the trend of COD, BOD, TSS and TDS removal. This indicates a decrease in adsorption capacity per unit mass of sorbent with the increase in sorbent dosage, potentially mitigating to some extent the trend observed in

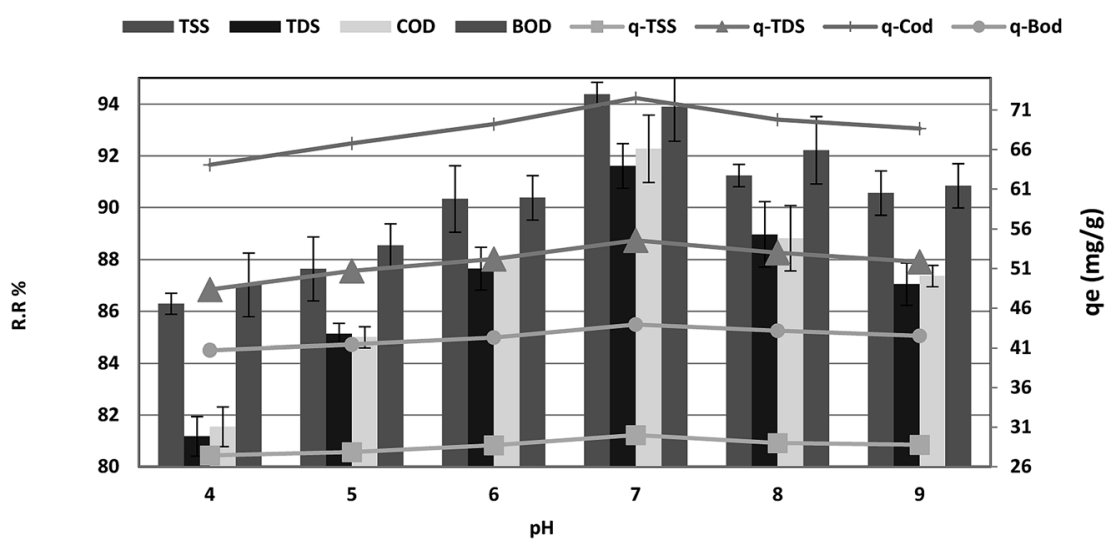

Fig. 6 Effect of $\mathrm{pH}$ on the removal efficiency and the adsorption capacity of BOD, COD, TSS and TDS at an adsorbent dose of $3.5 \mathrm{~g}$, contact time of $120 \mathrm{~min}$, and agitation speed of $150 \mathrm{rpm}$. 


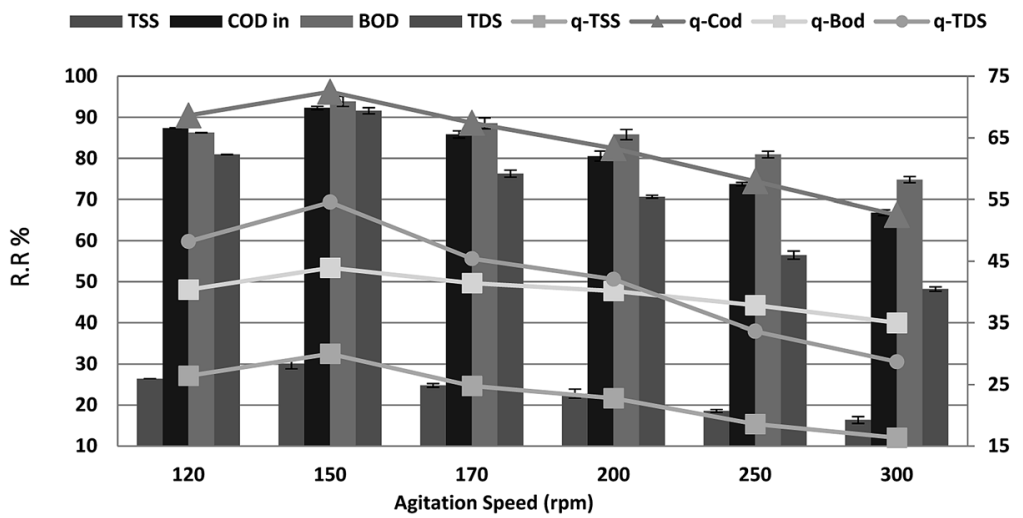

Fig. 7 Effect of agitation speed on the removal efficiency and the adsorption capacity of BOD, COD, TSS and TDS at an adsorbent dose of $3.5 \mathrm{~g}$, contact time of $120 \mathrm{~min}$, and $\mathrm{pH} 7$.

increasing removal efficiency with sorbent dosage. Interference among binding sites owing to increased biosorbent dosage cannot be ruled out as this will result in low specific uptake. ${ }^{30}$ The optimum adsorbent dosage for COD, BOD, TSS and TDS removal from aqueous solution by $P$. australis was $14 \mathrm{~g} \mathrm{~L}^{-1}$.

\subsection{Effect of contact time and adsorption kinetics}

The optimum contact time required for the adsorption of COD, BOD, TSS and TDS is important as it defines the time required for the adsorbates (COD, BOD, TSS and TDS) to reach an equilibrium state after contact with $P$. australis. The effect of contact time on the adsorption of COD, BOD, TSS and TDS onto $P$. australis is shown in Fig. 4 and 5.

The percent removal of COD increases with increasing contact time and biphasic kinetics are observed in each case. In the first instant, a rapid removal occurs within the first $90 \mathrm{~min}$ owing to a large number of available surface sites, representing the fast phase. The second stage is a slower adsorption phase process and causes smaller COD adsorption, which ended with an equilibrium point at $120 \mathrm{~min}$. At this point, most of the adsorption sites were already saturated to their maximum uptake capacity. A contact time of $120 \mathrm{~min}$ is regarded as the
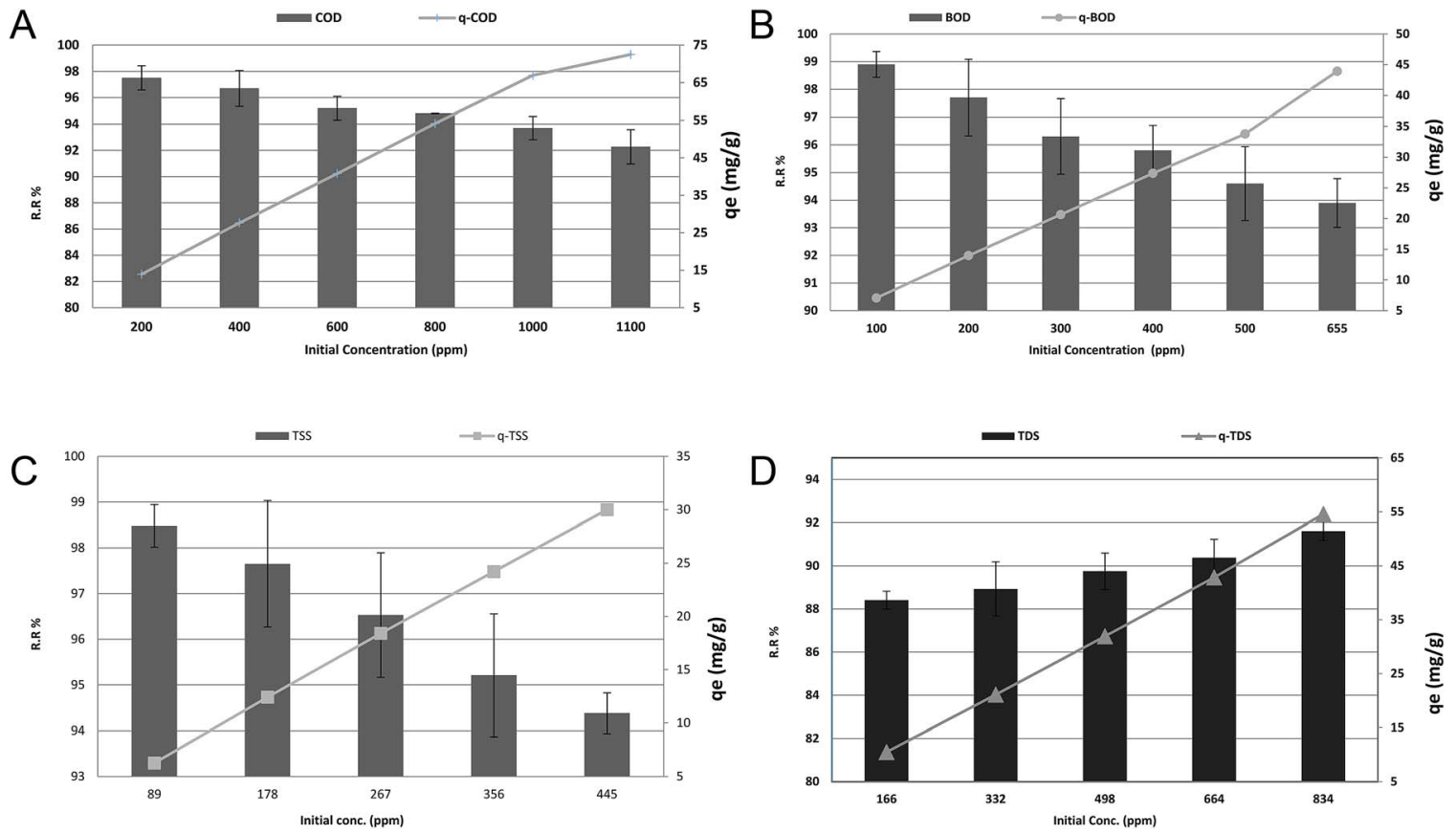

Fig. 8 (a) Effect of initial concentration on the removal efficiency and adsorption capacity of COD at an adsorbent dose of $3.5 \mathrm{~g}$, pH 7 , contact time of $120 \mathrm{~min}$ and agitation speed of $150 \mathrm{rpm}$. (b) Effect of initial concentration on the removal efficiency and adsorption capacity of BOD at an adsorbent dose of $3.5 \mathrm{~g}, \mathrm{pH}$ 7, contact time of $120 \mathrm{~min}$ and agitation speed of $150 \mathrm{rpm}$. (c) Effect of initial concentration on the removal efficiency and adsorption capacity of TSS at an adsorbent dose of $3.5 \mathrm{~g}, \mathrm{pH} 7$, contact time of 120 min and agitation speed of $150 \mathrm{rpm}$. (d) Effect of contact time on the removal efficiency and adsorption capacity of TDS at an adsorbent dose of $3.5 \mathrm{~g}, \mathrm{pH} 7$, contact time of 120 min and agitation speed of $150 \mathrm{rpm}$. 
Table 5 Parameters of the isotherm study (Langmuir and Freundlich models) for COD, BOD, oil and grease biosorption using Phragmites australis (at room temperature of $25.00 \pm 3.00^{\circ} \mathrm{C}$ )

\begin{tabular}{|c|c|c|c|}
\hline Reaction kinetics & Linear equation & Parameters & $R^{2}$ \\
\hline \multirow[t]{4}{*}{ Langmuir isotherm } & $Y_{\mathrm{COD}}=0.3051 x+0.0115$ & $q_{\mathrm{m}}=86.9565 \mathrm{mg} \mathrm{g}^{-1}, K_{\mathrm{l}}=0.0377 \mathrm{~L} \mathrm{mg}^{-1}$ & 0.9948 \\
\hline & $R_{\mathrm{L} \mathrm{COD}}=0.1171: 0.0235$ & The & \\
\hline & $R_{\mathrm{L} \mathrm{вOD}}=0.0399: 0.0063$ & & \\
\hline & $\begin{array}{l}Y_{\mathrm{TSS}}=0.1747 x+0.0324 \\
R_{\mathrm{L} \mathrm{TSS}}=0.0571: 0.0120\end{array}$ & $q_{\mathrm{m}}=30.8642 \mathrm{mg} \mathrm{g}^{-1}, K_{\mathrm{l}}=0.1855 \mathrm{~L} \mathrm{mg}^{-1}$ & 0.9912 \\
\hline \multirow[t]{4}{*}{ Freundlich isotherm } & $Y_{\mathrm{COD}}=0.5905 x+1.7352$ & $1 / n=0.5905 \mathrm{~L} \mathrm{~g}^{-1}, K_{\mathrm{f}}=5.6701 \mathrm{mg} \mathrm{g}^{-1}$ & 0.9920 \\
\hline & $Y_{\mathrm{BOD}}=0.5025 x+1.8798$ & $1 / n=0.5025 \mathrm{~L} \mathrm{~g}^{-1}, K_{\mathrm{f}}=6.5522 \mathrm{mg} \mathrm{g}^{-1}$ & 0.9970 \\
\hline & $Y_{\mathrm{TSS}}=0.5291 x+1.7114$ & $1 / n=0.5291 \mathrm{~L} \mathrm{~g}^{-1}, K_{\mathrm{f}}=5.5367 \mathrm{mg} \mathrm{g}^{-1}$ & 0.9980 \\
\hline & $Y_{\mathrm{TDS}}=1.2364 x+1.3494$ & $1 / n=1.2364 \mathrm{~L} \mathrm{~g}^{-1}, K_{\mathrm{f}}=0.2594 \mathrm{mg} \mathrm{g}^{-1}$ & 0.9890 \\
\hline
\end{tabular}

optimum time for high adsorption capacity of $P$. australis. After 120 min contact time, the amount of COD, BOD, TSS and TDS removed remained constant for all the adsorbents, which might be attributed to saturation of the adsorption sites as the contact time increased. A parallel trend was found by, ${ }^{31}$ who stated that the biphasic mechanism basically involves external and internal diffusion processes. The maximum percentage removal of COD, BOD, TSS and TDS gradually increased from $18.18 \%, 23.66 \%$, $19.10 \%$, and $14.39 \%$ to $81.55 \%, 87.02 \%, 86.29 \%$, and $81.18 \%$, respectively, with an increase in contact time from 10 to $120 \mathrm{~min}$, with ( $r$ 0.840, $p$ 0.002), ( $r$ 0.837, $p$ 0.003), $(r$ 0.799, $p$ $0.006)$ and $(r$ 0.785, $p$ 0.007) for COD, BOD, TSS and TDS, respectively. Similar behavior was observed for $q_{\mathrm{e}}$, which enhanced to $64.07,40.71,27.43$, and $48.36 \mathrm{mg} \mathrm{g}^{-1}$ for COD, BOD, TSS and TDS, respectively with the contact time up to 120 min, with ( $r$ 0.840, $p$ 0.002), (0.837, $p$ 0.003), ( $r$ 0.799, $p$ $0.006)$ and $(r 0.785, p 0.007)$ for COD, BOD, TSS and TDS, respectively.

Several kinetic models, such as the pseudo-first-order, pseudo-second-order and intraparticle diffusion models, have been applied to investigate the adsorption mechanism. ${ }^{28}$ The equations of the two kinetic models are expressed in Table 4, where $q_{t}$ and $q_{\mathrm{e}}\left(\mathrm{mg} \mathrm{g}^{-1}\right)$ are the amounts of COD, BOD, TSS and TDS sorbed at time $t$ and equilibrium ( $\mathrm{min}$ ), respectively. $k_{1}$ and $k_{2}\left(\mathrm{mg} \mathrm{g}^{-1} \mathrm{~min}^{-1}\right)$ are the rate constants of the pseudo-firstorder and pseudo-second order models, respectively. The corresponding linear parameters are presented in Table 4. Obviously, sorption of COD, BOD, TSS and TDS on Phragmites australis almost achieved equilibrium within the previous 120 min, indicating a high efficiency in sorbing COD, BOD, TSS and TDS.

The linear regression coefficients of the pseudo-secondorder model were $0.984,0.992,0.983$, and 0.961 , while they were $0.825,0.844,0.886$, and 0.889 for COD, BOD, TSS and TDS, respectively, for the pseudo-first-order model. Moreover, the equilibrium sorption amounts for COD, BOD, TSS and TDS calculated by the pseudo-second-order model were in good agreement with the experimental results as presented in Table 4. The above results indicate that sorption of COD, BOD, TSS and TDS on Phragmites australis could be described well by the pseudo-second-model, representing heterogeneous surface adsorption. This model clarifies the basis of the adsorption process, including the associations of valence powers or electron trade amongst the adsorbent and adsorbate. ${ }^{28} \mathrm{COD}$, BOD, TSS and TDS could be well correlated with the pseudo-second order-model representing the heterogeneous surfaces adsorption. Consequently, the sorption mechanism is ascribed to chemisorption.

\section{4 pH effect}

The effect of $\mathrm{pH}$ on the adsorption of COD, BOD, TSS and TDS at an equilibrium contact time of $120 \mathrm{~min}$ is shown in Fig. 6. It is demonstrated that the adsorption percentage of COD, BOD, TSS and TDS onto $P$. australis increased with an increase in the $\mathrm{pH}$ from 4.0-7.0 and reduced in alkaline solution. This trend is explained by the competitive adsorption between aqueous $\mathrm{H}^{+}$ ions and COD, BOD, TSS, TDS on the surface-active sites of $P$. australis at lower $\mathrm{pH}$. A positive charge causes strong electrostatic interactions between COD, BOD, TSS and TDS and $P$. australis. $^{32}$ The amount of COD, BOD, TSS and TDS removal increased gradually from $81.55 \%, 87.02 \%, 86.29 \%$, and $81.18 \%$ to $92.27 \%, 93.89 \%, 94.38 \%$, and $91.61 \%$, respectively, with an increase in $\mathrm{pH}$ from 4 to 7 , with $(r$ 0.998, $p$ 0.002), $(r 0.979, p$ $0.021),(r 0.976, p 0.024)$ and $(r 0.996, p 0.004)$ for COD, BOD, TSS and TDS, respectively. Similar behavior was observed for $q_{\mathrm{e}}$, which enhanced to $72.50,43.93,30.00$, and $54.57 \mathrm{mg} \mathrm{g}^{-1}$ with $\mathrm{pH}$ up to 7 with $(r 0.998, p 0.002),(r 0.979, p 0.021),(r 0.976, p$ $0.024)$ and ( $r$ 0.996, $p$ 0.004) for COD, BOD, TSS and TDS, respectively. With increasing $\mathrm{pH}$, the COD, BOD, TSS and TDS sorption capacity decreased at $\mathrm{pH}$ values from 7.0 to 9 . The COD, BOD, TSS and TDS removal ratio dropped to $87.36 \%$, $90.84 \%, 90.56 \%$, and $87.05 \%$, with $(r-0.973, p 0.147),(-0.998$, $p$ 0.037), $(r-0.937, p 0.228)$ and $(r-0.996, p 0.058)$, respectively. In the same manner, $q_{\mathrm{e}}$ dropped to $68.64,42.5,28.79$, and $51.86 \mathrm{mg} \mathrm{g}^{-1}$ at pH 9 with $(r-0.973, p 0.147),(r-0.998, p 0.037)$, $(r-0.937, p 0.228)$ and $(r-0.996, p 0.058)$ for COD, BOD, TSS and TDS, respectively. It can be seen that $P$. australis may perform well in neutral solutions but not in alkaline solutions. When the $\mathrm{pH}$ decreased, $\mathrm{H}^{+}$ions increased in the wastewater solution and the adsorbent surface carried more negative 
Table 6 Comparison between the present study and previous studies for the biosorption of COD from point of view of operating parameters

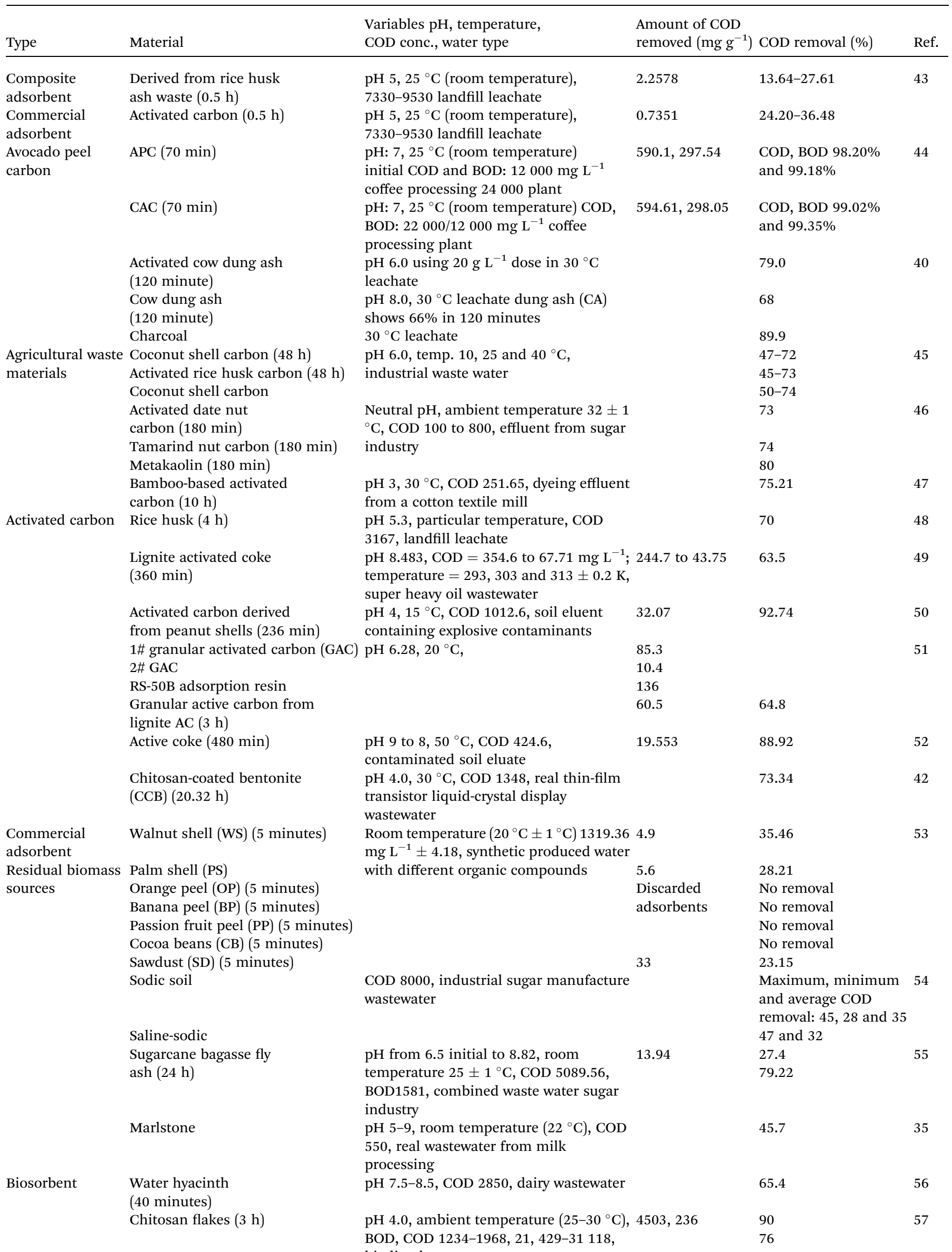


Table 6 (Contd.)

\begin{tabular}{|c|c|c|c|c|c|}
\hline Type & Material & $\begin{array}{l}\text { Variables } \mathrm{pH} \text {, temperature, } \\
\text { COD conc., water type }\end{array}$ & $\begin{array}{l}\text { Amount of COD } \\
\text { removed }\left(\mathrm{mg} \mathrm{g}^{-1}\right)\end{array}$ & COD removal (\%) & Ref. \\
\hline Dried biomass & $\begin{array}{l}\text { Phragmites australis } \\
(2 \mathrm{~h})\end{array}$ & $\begin{array}{l}\text { Room temp. }\left(25^{\circ} \mathrm{C}\right) \mathrm{pH} 7, \mathrm{COD} \\
200: 1100, \text { BOD } 100: 655 \text {, TSS } 89: 445 \\
\text { TDS } 166: 834 \mathrm{mg} \mathrm{L}^{-1}\end{array}$ & $\begin{array}{l}86.9565 \\
33.0033 \\
30.8642 \\
54.57\end{array}$ & $\begin{array}{l}\text { COD } 97.5: 92.27 \\
\text { BOD } 98.9: 93.89 \\
\text { TSS } 98.48: 94.38 \\
\text { TDS } 88.41: 91.61\end{array}$ & $\begin{array}{l}\text { This } \\
\text { study }\end{array}$ \\
\hline
\end{tabular}

charge, causing greater attraction between the adsorbent and the cationic form of the adsorbate. When the $\mathrm{pH}$ of the wastewater solution increases $(\mathrm{pH}>7)$, excess $\mathrm{OH}^{-}$ions for the adsorption sites produce a repulsion force towards the organic molecules' (COD, BOD, TSS and TDS) cations with negatively charged functional groups in the adsorbent surface. This could take place thus reducing the adsorption capacity. ${ }^{2,33} \mathrm{pH}$ is a typical parameter in the adsorption process owing to its effect on the speciation of pollutants. ${ }^{34}$

\subsection{Agitation speed effect}

The maximum COD reduction was observed at $150 \mathrm{rpm}$, as shown in Fig. 7. Above $150 \mathrm{rpm}$, the loosely attached molecules might re-enter into the adsorbate, lowering the \% COD reduction. Therefore, we kept the agitation speed at $150 \mathrm{rpm}$. The maximum removal efficiencies of $92.27 \%, 93.89 \%, 94.38 \%$ and $91.61 \%$ were recorded at agitation speeds from 120 to $150 \mathrm{rpm}$ for COD, BOD, TSS and TDS, respectively, after which a significant decrease was noticed. When the agitation speed was increased from 150 to $300 \mathrm{rpm}$, the results were as follows: $(r-$ $0.989, p 0.001),(r-0.988, p 0.002),(r-0.959, p 0.01)$ and $(r-$ $0.970, p$ 0.006) for COD, BOD, TSS and TDS, respectively. Moreover, $q_{\mathrm{e}}$ showed a dramatic increase from 68.64, 40.36, 26.43 , and 48.21 to $72.50,43.93,30.00$, and $54.57 \mathrm{mg} \mathrm{g}^{-1}$ for COD, BOD, TSS and TDS, respectively, with an increase in agitation speed from 120 to $150 \mathrm{rpm}$. In some instances, external film diffusion can affect the biosorption process. Constant agitation can minimize this mass transfer resistance. Moreover, by increasing the agitation rate, the diffusion rate of a solute from the bulk liquid to the boundary layer liquid surrounding particles becomes higher owing to enhanced turbulence as the thickness of the liquid boundary layer decreases. $^{30}$

However, further increase in agitation speed from 150 to $300 \mathrm{rpm}$ showed a decrease in the $q_{\mathrm{e}}$ to $52.50,35.00,16.36$, and
$28.71 \mathrm{mg} \mathrm{g}^{-1}$ with the same $(r, p)$ for the COD, BOD, TSS and TDS removal ratio, respectively. This may be attributed to the dispersal of the adsorbent particles. Because of the fact that the adsorption process is mass transfer motivated, it is thought that the liquid side mass transfer resistance controls the process. Thus, the adsorption rate increases with bulk motion. ${ }^{35}$ With increasing blending speed, the adsorption limit of COD, BOD, TSS and TDS diminished. This behavior was interpreted as follows: higher agitation speed lowered the biosorption capacity owing to utilization of all biosorption sites of the adsorbent. In addition, there is a higher chance that desorption could occur at high speed. ${ }^{34}$ This shows that the dispersion of COD, BOD, TSS and TDS particles from wastewater solution to the surface of the adsorbent and into the pores happens effortlessly and rapidly. This is because of the powder of the adsorbents. Restabilization of suspended will happen when the blending speed is quick. This phenomenon can be obviously observed for readings of blending speeds above $150 \mathrm{rpm} .{ }^{36}$ Phragmites australis showed the most stringent changes, which proves that Phragmites australis is a good binder.

\subsection{Effect of initial COD, BOD, TSS and TDS concentrations and adsorption isotherms}

To evaluate the effect of COD, BOD, TSS, and TDS concentration on the adsorption efficiency removal, the adsorption process was gradually tested within the average COD, BOD, TSS and TDS concentrations in the examined wastewater, as previously displayed in Table 1, to low concentrations. The results in Fig. 8a, $\mathrm{b}$ and $\mathrm{c}$ revealed that increasing the initial COD, BOD and TSS concentrations could linearly decrease the removal ratio from $97.5 \%, 98.9 \%$, and $98.48 \%$ to $92.27 \%, 93.89 \%$, and $94.38 \%$, with $(r-0.981, p 0.001),(r-0.984, p 0.000)$ and $(r-0.997, p$ 0.000 ), respectively. While, as shown in Fig. 8d, increasing the initial TDS concentration linearly increased the removal ratio from $88.41 \%$ to $91.61 \%$ with ( $r 0.989, p 0.001)$. On the other

Table 7 Comparison between the present study and previous studies for the biosorption of COD from point of view of isotherm models

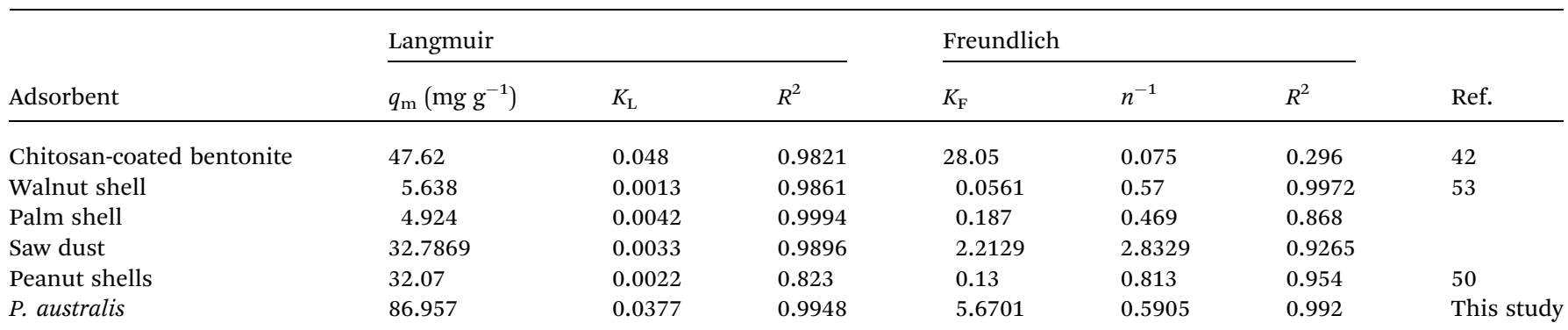


Table 8 Comparison between the present study and previous studies for the biosorption of COD from point of view of kinetics models

\begin{tabular}{|c|c|c|c|c|c|c|c|}
\hline Adsorbent & Pollutant & Model & $R^{2}$ & $K_{1}\left(\mathrm{mg} \mathrm{g}^{-1} \min ^{-1}\right)$ & $K_{2}\left(\mathrm{mg} \mathrm{g}^{-1} \min ^{-1}\right)$ & $K_{\mathrm{id}}$ & Ref. \\
\hline Marlstone particles & \multirow[t]{2}{*}{ COD } & Pseudo-first order & 0.9826 & 1.496 & - & - & \multirow[t]{2}{*}{35} \\
\hline Marlstone particles & & Pseudo-second order & 0.9984 & - & 1.1998 & - & \\
\hline Peanut shells & COD & Pseudo-second order & 0.999 & - & 0.0526 & - & 50 \\
\hline Supermagnetic nanoparticles & \multirow[t]{2}{*}{ COD } & Pseudo-first order & 0.9661 & 0.00585 & - & - & \multirow[t]{2}{*}{58} \\
\hline Supermagnetic nanoparticles & & Pseudo-second order & 0.944 & - & 0.0000166 & - & \\
\hline Walnut shell & \multirow[t]{2}{*}{ COD } & Pseudo-first order & 0.9992 & 0.1991 & - & - & \multirow{2}{*}{53} \\
\hline Walnut shell & & Pseudo-second order & 0.6616 & - & 0.0343 & - & \\
\hline \multirow[t]{3}{*}{ Chitosan-coated bentonite } & \multirow[t]{3}{*}{ COD } & Pseudo-first order & 0.8661 & 0.17 & - & - & \multirow[t]{3}{*}{42} \\
\hline & & Pseudo-second order & 0.998 & - & 0.09 & - & \\
\hline & & Weber and Morris & 0.8091 & - & - & 0.69 & \\
\hline P. australis & COD & Pseudo-first order & 0.825 & 0.076 & - & - & \multirow[t]{2}{*}{ This study } \\
\hline & & Weber and Morris & 0.841 & - & - & 2.7803 & \\
\hline \multirow[t]{3}{*}{ P. australis } & \multirow[t]{3}{*}{ TSS } & Pseudo-first order & 0.886 & 0.0663 & - & - & \\
\hline & & Pseudo-second order & 0.983 & - & 0.001158 & - & \\
\hline & & Weber and Morris & 0.786 & - & - & 1.8366 & \\
\hline \multirow{3}{*}{ P. australis } & \multirow{3}{*}{ TDS } & Pseudo-first order & 0.889 & 0.746 & - & - & \\
\hline & & Pseudo-second order & 0.961 & - & 0.000534 & - & \\
\hline & & Weber and Morris & 0.768 & - & - & 3.4028 & \\
\hline
\end{tabular}

hand, the $q_{\mathrm{e}}$ increased from 13.93, 7.06, 6.26, and 10.48 to 72.5 , $43.93,30.00$, and 54.57 for COD, BOD, TSS and TDS, respectively, with $(r 1, p 0.00)$ for all. It was evident that the increase in the initial concentration of COD, BOD and TSS resulted in a decrease in the percent removal and an increase in the uptake capacity. The higher initial concentrations of COD, BOD, TSS and TDS with a fixed amount of adsorbent will result in higher equilibrium concentrations of COD, BOD, TSS and TDS in the solution, which contributes to higher amounts of COD, BOD, TSS and TDS being adsorbed by the adsorbent. At low COD, BOD and TSS loads, the number of ions competing for the existing active sites in the biomass was reduced, and therefore there was adequate surface area to lodge the COD, BOD and TSS available in the solution. In addition, the reduction of the number of available adsorption sites on the surface is one of the reasons for the reduction because the ratio of COD, BOD and
TSS molecules to the adsorbent dosage rises with the elevation of the initial load. In the case of TDS, reduction of TDS, in general, has been found to increase with the increase in the initial TDS concentration. This was expected because the resistance to the diffusion of the adsorbate from the solution decreases with the increasing adsorbate load. The adsorption rate rises owing to the increasing driving force. ${ }^{3}$

For more information about Langmuir parameters, the reader is referred to ref. 26. As shown in Table 5, the values of $q_{\text {max }}, K_{\mathrm{L}}$ and regression coefficient $R^{2}$ are 86.9565, 33.003, 30.8642 , and $-116.2791 \mathrm{mg} \mathrm{g}^{-1}, 0.03769,0.02403,0.18546$, and $-4.2744 \times 10^{-3} \mathrm{~L} \mathrm{mg}^{-1}$, and 0.9948, 0.9594, 0.9912, and 0.9985 for COD, BOD, TSS, TDS, respectively. A negative value for the intercept, in essence the uptake of the monolayer, is physical nonsense. It may be due to the decrease in charge density and adsorption capacity as the ionic radius increases. The $R_{\mathrm{L}}$ for

Table $9 t$ Statistics and $p$-values for coefficients of a pure-quadratic regression model (for COD)

\begin{tabular}{|c|c|c|c|c|c|}
\hline$\beta_{0}$ & -21.4504 & 24.45549 & -0.87712 & 0.389118 & Insignificant \\
\hline$\beta_{1}$ & 16.98549 & 5.864011 & 2.896564 & 0.007924 & Significant \\
\hline$\beta_{3}$ & 1.042557 & 0.077829 & 13.39546 & $1.24 \times 10^{-12}$ & Significant \\
\hline$\beta_{4}$ & 0.010994 & 0.19712 & 0.055774 & 0.955983 & Insignificant \\
\hline$\beta_{5}$ & 5.255743 & 4.959888 & 1.05965 & 0.299853 & Insignificant \\
\hline$\beta_{8}$ & -0.00397 & 0.000425 & -9.33486 & $1.85 \times 10^{-9}$ & Significant \\
\hline$\beta_{9}$ & -0.00037 & 0.000463 & -0.80724 & 0.427458 & Insignificant \\
\hline$\beta_{10}$ & -0.3677 & 0.40982 & -0.89723 & 0.37851 & Insignificant \\
\hline
\end{tabular}


Table $10 t$ Statistics and $p$-values for coefficients of a pure-quadratic regression model (for BOD)

\begin{tabular}{|c|c|c|c|c|c|}
\hline & Estimate & Standard error & $t$ Ratio & Prob. $>|t|$ & Effect \\
\hline$\beta_{0}$ & -27.6128 & 24.52864 & -1.12574 & 0.271409 & Insignificant \\
\hline$\beta_{1}$ & 17.52678 & 6.095145 & 2.875532 & 0.008325 & Significant \\
\hline$\beta_{2}$ & 0.016085 & 0.020162 & 0.797794 & 0.432814 & Insignificant \\
\hline$\beta_{3}$ & 1.06009 & 0.08001 & 13.24944 & $1.57 \times 10^{-12}$ & Significant \\
\hline$\beta_{4}$ & 0.012168 & 0.197795 & 0.061517 & 0.951457 & Insignificant \\
\hline$\beta_{5}$ & 4.532874 & 4.929535 & 0.919534 & 0.366967 & Insignificant \\
\hline$\beta_{6}$ & -1.49156 & 1.421889 & -1.049 & 0.304628 & Insignificant \\
\hline$\beta_{7}$ & $-1.91 \times 10^{-5}$ & $1.36 \times 10^{-5}$ & -1.40589 & 0.172573 & Insignificant \\
\hline$\beta_{8}$ & -0.00404 & 0.000432 & -9.33989 & $1.83 \times 10^{-9}$ & Significant \\
\hline$\beta_{9}$ & -0.00037 & 0.000465 & -0.79977 & 0.431687 & Insignificant \\
\hline$\beta_{10}$ & -0.31415 & 0.407606 & -0.77072 & 0.448394 & Insignificant \\
\hline
\end{tabular}

Table $11 t$ Statistics and $p$-values for coefficients of a pure-quadratic regression model (for TSS)

\begin{tabular}{lcccll}
\hline & Estimate & Standard error & $t$ Ratio & Prob. $>|t|$ & Effect \\
\hline$\beta_{0}$ & 42.63803 & 40.51244 & 1.052468 & 0.303517 & Insignificant \\
$\beta_{1}$ & 21.73281 & 9.60698 & 2.26219 & 0.033442 & Significant \\
$\beta_{2}$ & 0.041681 & 0.099458 & 0.419078 & 0.679047 & Insignificant \\
$\beta_{3}$ & 1.04609 & 0.127516 & 8.203627 & $2.78 \times 10^{-8}$ & Significant \\
$\beta_{4}$ & -0.13051 & 0.322946 & -0.40413 & 0.689852 & Insignificant \\
$\beta_{5}$ & -7.29601 & 8.185479 & -0.89134 & 0.381979 & Insignificant \\
$\beta_{6}$ & -3.27631 & 2.165309 & -1.51309 & 0.143877 & Insignificant \\
$\beta_{7}$ & -0.00013 & 0.000169 & -0.77049 & 0.448854 & Insignificant \\
$\beta_{8}$ & -0.00409 & 0.000696 & -5.87471 & $5.48 \times 10^{-6}$ & Significant \\
$\beta_{9}$ & -0.0003 & 0.000759 & -0.39118 & 0.699264 & Insignificant \\
$\beta_{10}$ & 0.558893 & 0.675577 & 0.827282 & 0.416578 & Insignificant
\end{tabular}

COD, BOD, TSS and TDS adsorption by Phragmites australis was found to be $0.1171: 0.02355$ for concentrations of 200$1100 \mathrm{mg} \mathrm{L}^{-1}$ of COD, $0.03995-6.314 \times 10^{-3}$ for concentrations of 100-655 $\mathrm{mg} \mathrm{L}^{-1}$ of BOD, 0.0571-0.01197 for concentration of 89-445 $\mathrm{mg} \mathrm{L}^{-1}$ of TSS and 3.44294- $(-0.389886)$ for concentrations of $166-834 \mathrm{mg} \mathrm{L}^{-1}$ of TDS. The values of $R_{\mathrm{L}}$ for COD, BOD, TSS are in the range of $0-1$, which indicates favorable adsorption, while TDS is unfavorable $\left(R_{\mathrm{L}}<1\right)$.

The interested reader is referred to papers by ref. 37 and 38 for more information about Freundlich equilibrium constants and their indicators. When $n$ is greater than 1 , the isotherm is concave downward; when $n$ is less than 1 , the isotherm is concave upward; and when $n$ is equal to 1 , the isotherm is linear. For TDS, it shows an $n$ value of less than 1 . Owing to the higher ionic radius of TDS, adsorption of TDS on Phragmites australis is very difficult and for this reason it may show less exchange capacity. Since $n$ is between 1 and 10, this indicates favorable adsorption of COD, BOD and TSS onto Phragmites australis. As displayed in Table 5, the regression coefficients $R^{2}$ are $0.992,0.997,0.998$, and 0.989 for COD, BOD, TSS and TDS, respectively, which is regarded as a measure of the goodness of fit of the experimental data to the isotherm models. The Freundlich model is nearly coincident with the Langmuir model for the representation of the adsorption data because it has higher $R^{2}$ values. Except for that, both the Freundlich model and the Langmuir model could be suitable for COD. The values of $K_{\mathrm{F}}$ and $1 / n$ were $5.6701,6.5522,5.5367$, and $0.2594 \mathrm{mg} \mathrm{g}^{-1}$ and $0.5905,0.5025,0.5291$, and $1.2364 \mathrm{~L} \mathrm{~g}^{-1}$ for COD, BOD, TSS and TDS, respectively.

3.6.1 Comparison with other materials. A great variety of different types of materials for COD removal have been described in previous studies. Authors such as ${ }^{39-58}$ listed different adsorbents employed for COD from different wastewater types, categorized as: natural materials, industrial byproducts and developed products that have been used as adsorbents for COD removal. Based on these studies, we can compare the yield of COD removal of many materials with the results obtained for the Phragmites australis material. Tables 6, 7 and 8 shows the efficiency reported for some materials,

Table $12 t$ Statistics and $p$-values for coefficients of a pure-quadratic regression model (for TDS)

\begin{tabular}{|c|c|c|c|c|c|}
\hline & Estimate & Standard error & $t$ Ratio & Prob. $>|t|$ & Effect \\
\hline$\beta_{0}$ & 9.378485 & 40.71209 & 0.230361 & 0.819848 & Insignificant \\
\hline$\beta_{1}$ & 22.33025 & 9.656334 & 2.312497 & 0.030047 & Significant \\
\hline$\beta_{3}$ & 1.057796 & 0.128171 & 8.253026 & $2.50 \times 10^{-8}$ & Significant \\
\hline$\beta_{4}$ & -0.062 & 0.324605 & -0.191 & 0.850202 & Insignificant \\
\hline$\beta_{5}$ & -3.35297 & 8.22849 & -0.40748 & 0.687421 & Insignificant \\
\hline$\beta_{8}$ & -0.00419 & 0.0007 & -5.98465 & $4.21 \times 10^{-6}$ & Significant \\
\hline$\beta_{9}$ & -0.00046 & 0.000763 & -0.60708 & 0.549747 & Insignificant \\
\hline$\beta_{10}$ & 0.272288 & 0.679115 & 0.400945 & 0.692161 & Insignificant \\
\hline
\end{tabular}




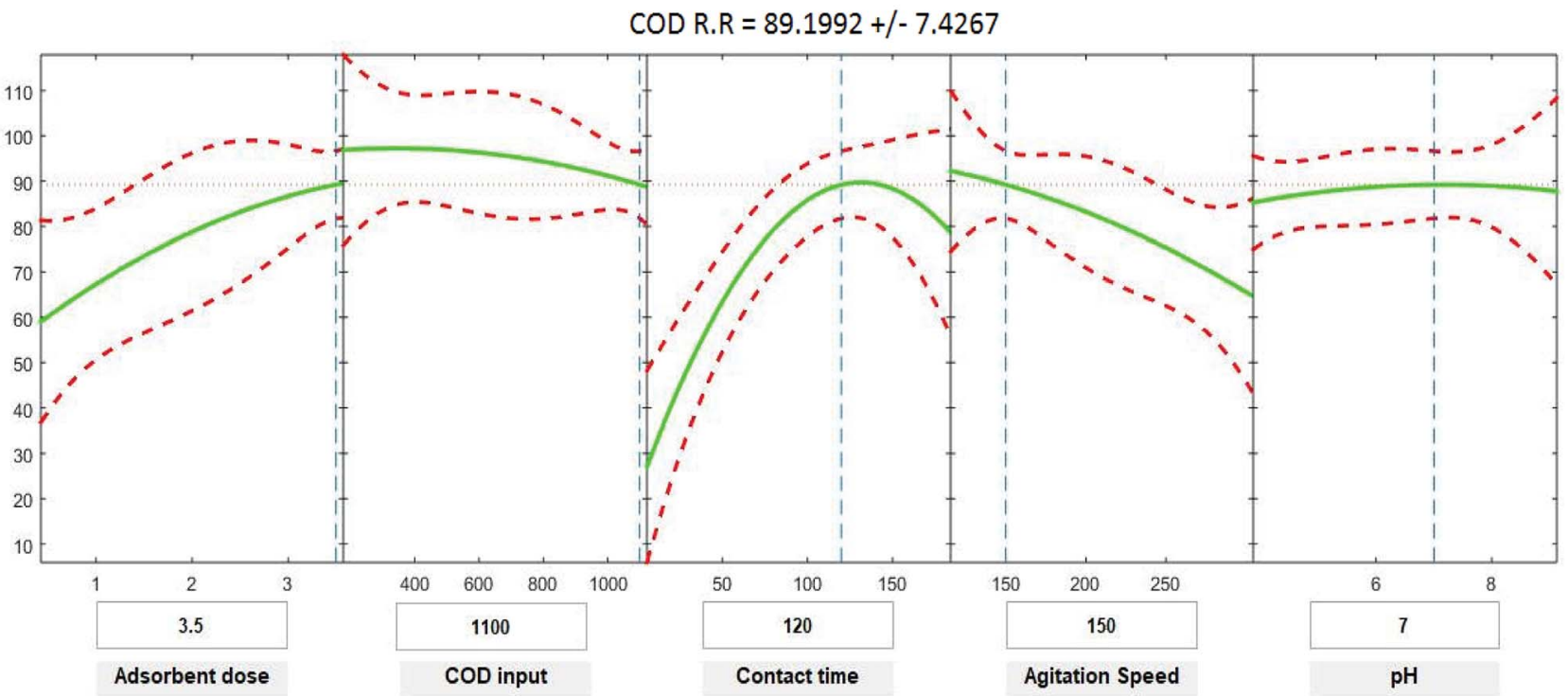

Fig. 9 Interactive response surface methodology for estimation of COD removal efficiency using the independent variables: $\mathrm{pH}$, initial COD concentration, contact time, agitation speed and adsorbent dose.

adsorption isotherms and kinetic studies, respectively, for removing COD from wastewater on laboratory scale. As per these examinations, materials such as chitosan flakes, avocado peel carbon and Phragmites australis are considered among the best in their particular classes.

The experimental capacity of Phragmites australis was the fourth best after chitosan flakes, avocado peel carbon and lignite activated coke, because the amount of adsorbed COD at equilibrium decreases when the COD concentration is reduced. This resulted in a driving force induced by the reduction in the concentration gradient.
The present authors found that Phragmites australis dried biomass is an effective biosorbent for COD, BOD, TSS and TDS, removal exhibiting the potentiality of finding locally available materials with high pollutant maintenance limit with regards to use in wastewater treatment. Phragmites australis kept the first position in the capacity for COD biosorption, as indicated in Table 7 according to Langmuir, in addition to the highest removal ratio among the different adsorbents. Phragmites australis is very interesting and novel owing to organic pollutants in wastewater being a worldwide problem. Another important point obtained in this study is the use of clean technology,

BOD R.R $=96.6641+/-11.6093$

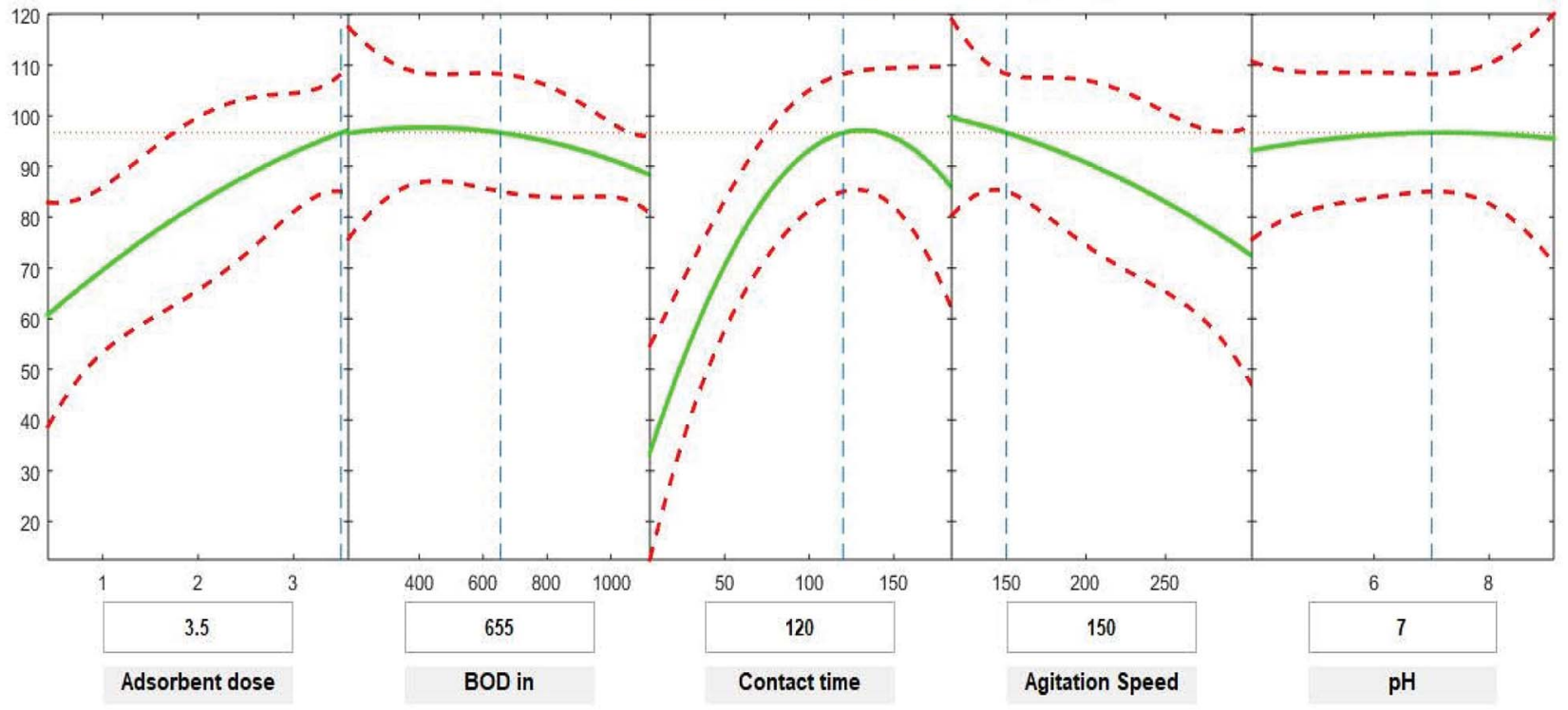

Fig. 10 Interactive response surface methodology for estimation of BOD removal efficiency using the independent variables: $\mathrm{pH}$, initial $\mathrm{BOD}$ concentration, contact time, agitation speed and adsorbent dose. 
TSS R.R $=87.975+/-12.5227$

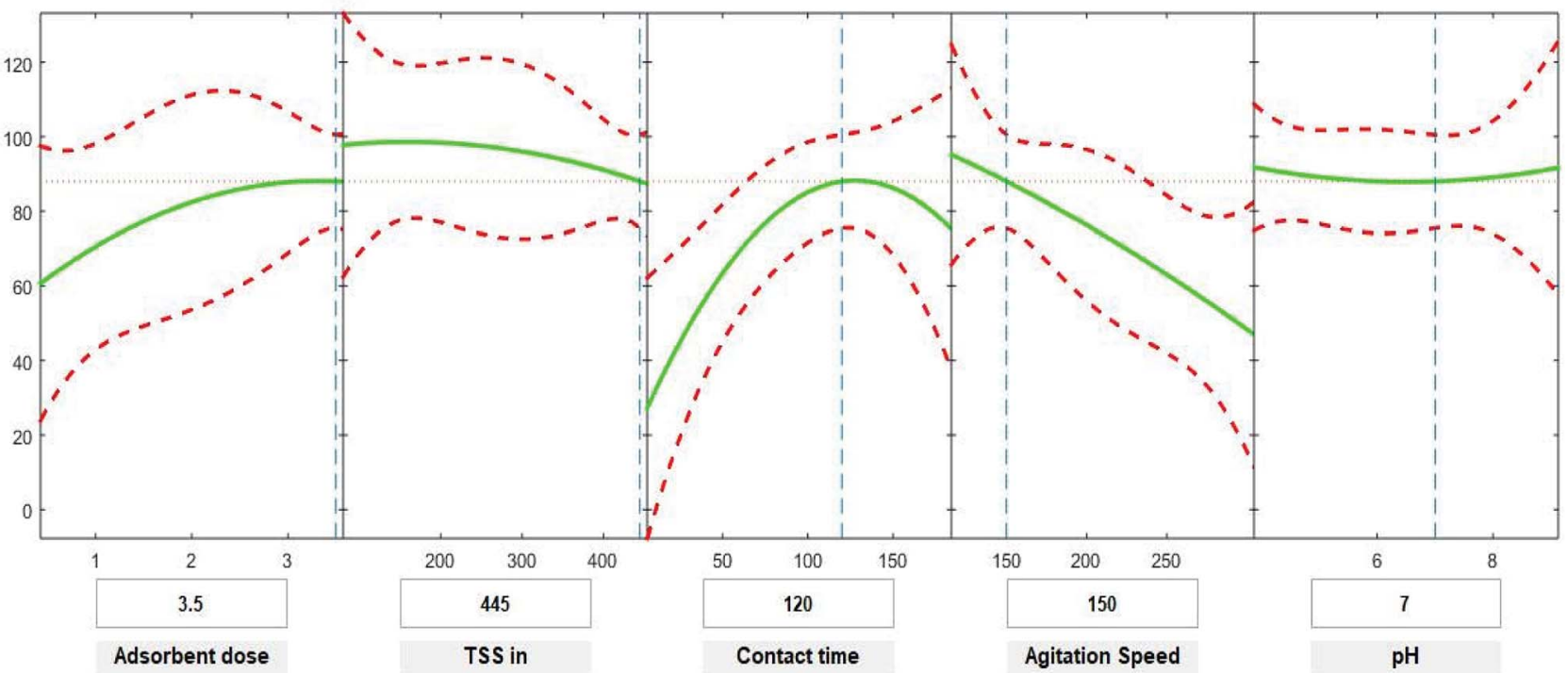

Fig. 11 Interactive response surface methodology for estimation of TSS removal efficiency using the independent variables: $\mathrm{pH}$, initial TSS concentration, contact time, agitation speed and adsorbent dose.

which is economical and environmentally friendly. Phragmites australis yields high capacity removal of all studied pollutants at the same time with the same condition with another important result of highest capacity organic pollutants removal at $\mathrm{pH} 7$. Furthermore, the majority of the studies published in the literature focused on synthetic solutions with only a few studies using real wastewater.

The results revealed that the adsorption of organic contaminants on crude Phragmites australis was positive in different manners. For example, ease of accessibility to Phragmites australis, delegated amongst the most adequate feedstock for approval, simple flexibility to various environmental conditions, high biomass profitability and capacity to accelerate development. Additionally, it is a natural and cost-effective material. Preparation of dried Phragmites australis biomass powder is costless compared to other materials that require chemical additives. These chemical additives are ecologically unsafe. The current study demonstrated that COD removal costs by Phragmites australis are estimated at $0.28-0.3 \$$ per $g$ COD removal. On the contrary, the COD removal costs using

TDS R.R $=85.7786+/-12.5914$

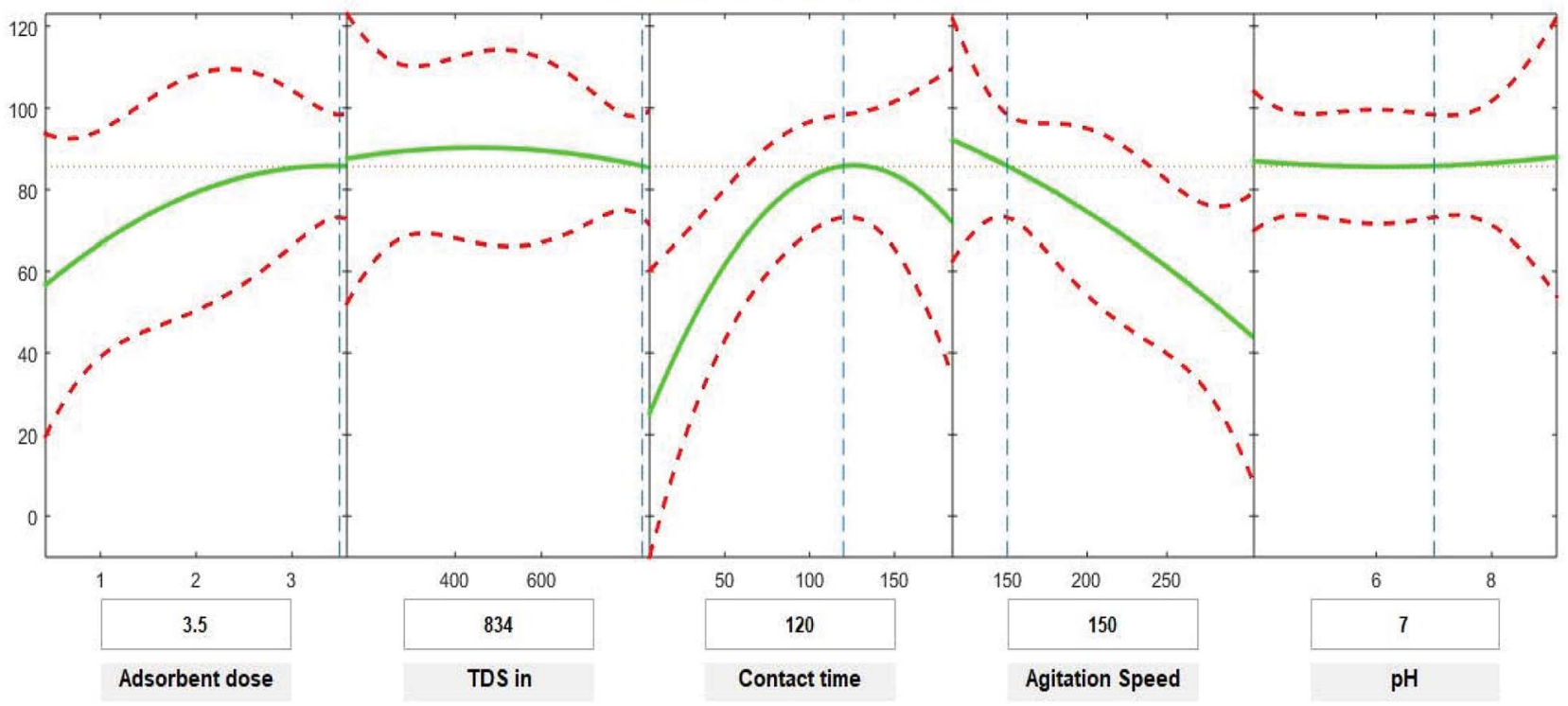

Fig. 12 Interactive response surface methodology for estimation of TDS removal efficiency using the independent variables: $\mathrm{pH}$, initial TDS concentration, contact time, agitation speed and adsorbent dose. 
chitosan flakes, lignite activated coke and avocado peel carbon were estimated to be 15 and 10 \$ per g COD removal, respectively, i.e. the cost is 30-50 times higher compared to Phragmites australis. Owing to the fact that few researchers have reported on TSS and TDS removal by adsorption, the efficiency comparison among different adsorbents was conducted only for COD and BOD. This was because COD and BOD are considered the main indicators of water pollution. Recently, the present authors published a study of the use of Phragmites australis dried biomass in oily wastewater. It achieved high capacity in retaining COD, BOD and oil and grease. ${ }^{23}$ It can be deduced that Phragmites australis achieved high efficiency in low and high initial pollutants concentrations.

\subsection{Statistical analysis for COD, BOD, TSS and TDS}

Positive linear effects of the independent variables "adsorbent dose", and "contact time" on COD, BOD, TSS and TDS removal were observed to be significant $(p<0.05)$, as listed in Tables 912. Additionally, a significant negative effect $(p<0.05)$ was perceived for the quadratic term of "contact time". However, insignificant effects $(p>0.05)$ were determined for the linear terms of "initial COD, BOD, TSS and TDS concentration", "agitation speed", and "pH", as well as quadratic terms of "adsorbent dose", "pH", "agitation speed", and "initial COD, BOD, TSS and TDS concentration". The coefficient of determination between the measured data and simulated results $\left(r^{2}\right)$, adjusted $r^{2}$, and mean squared error were $(0.9883,0.9874,0.961$, and 0.9614), (0.9835, 0.9821, 0.9441, and 0.9446) and (12.941, 13.031, 34.7331, and 35.091) for COD, BOD, TSS and TDS, respectively. The high $r^{2}$ value recommended the reliability of the proposed model. For simplicity, the insignificant factors were excluded, and a new regression model was obtained, as shown in eqn (3)-(6).

$$
\begin{aligned}
Y_{\mathrm{COD}}= & 4.29+8.82 X_{1}+1.0982 X_{3}-0.000009 X_{2}^{2} \\
& -0.004232 X_{3}^{2}-0.000323 X_{4}^{2} \\
Y_{\mathrm{BOD}}= & -2.72+10.94 X_{1}+1.1100 X_{3}-0.004275 X_{3}^{2} \\
& -0.000319 X_{4}^{2}-0.000010 X_{2}^{2} \\
Y_{\mathrm{TSS}}= & 52.32+7.54 X_{1}+0.950 X_{3}-0.2678 X_{4} \\
& -0.003669 X_{3}^{2}-0.000052 X_{2}^{2} \\
Y_{\mathrm{TDS}}= & 8.37+8.00 X_{1}+1.0261 X_{3} \\
& -0.004062 X_{3}^{2}-0.000629 X_{4}^{2}
\end{aligned}
$$

where $Y$ is the predicted response of COD, BOD, TSS and TDS removal efficiency (\%); $X_{1}$ is adsorbent dose $(0.5-3.5) ; X_{2}$ is agitation speed (120-300 rpm); and $X_{3}$ is contact time (10-180 min). The plot in Fig. 9-12 show a contour of IRSM for COD, BOD, TSS and TDS removal efficiency against the studied factors, $\mathrm{pH}$, initial COD, BOD, TSS and TDS concentration, time, stirring speed, and biosorbent dose. The IRSM plots a 95\% simultaneous confidence band for the fitted response surface as two red curves. The studied factors affecting the biosorption process are exhibited in the text boxes on the horizontal axes and are noticeable by vertical dashed blue lines in the plots. The green lines in Fig. 9-12 correspond to the purequadratic regression models in eqn (1) in Section 2.7. For example, at pH 7, COD, BOD, TSS and TDS concentrations of $1100,655,445$, and $834 \mathrm{mg} \mathrm{L} \mathrm{L}^{-1}$, contact time of $120 \mathrm{~min}$, agitation speed of $150 \mathrm{rpm}$, and biomass dosage of $3.5 \mathrm{~g}$, the predicted COD, BOD, TSS, and TDS removal efficiency could be estimated as $89.19992 \%, 96.6641 \%, 87.975 \%$, and $85.7786 \%$, respectively. The COD, BOD, TSS, and TDS removal efficiency from IRSM approximately matched the actual values of $92.27 \%$, $93.89 \%, 94.38 \%$, and $91.61 \%$ under the equivalent experimental condition.

\section{Conclusion}

The present study concluded that FTIR results reveal that a large amount of chemical functional groups were preserved and generated on the surface of $P$. australis, which might enhance its adsorptive properties owing to the functional groups $-\mathrm{OH}, \mathrm{CH}_{2}$, $\mathrm{C}-\mathrm{O}$ and $\mathrm{C}=\mathrm{C}$. The SEM analysis showed confirmation of the adsorption process owing to the surface texture of the examined plant. This study demonstrated that $P$. australis can reduce the organic load (COD, BOD, TSS and TDS) in domestic wastewater and achieved higher removal ratios compared to other agrowastes. It was also found that a large amount of chemical functional groups were conserved on the surface of $P$. australis, with great biosorption capacity of COD, BOD, TSS and TDS at $\mathrm{pH}$ 7. The batch adsorption study showed that the removal of COD was well-matched with the Langmuir isotherm model. This demonstrates that the adsorption occurred by monolayer adsorption because of particular holding amongst the adsorbate and the surface of the adsorbent. On the other hand, the removal of COD, BOD, TSS and TDS was well-fitted with the Freundlich isotherm model, which indicates multilayer adsorption taking place on the innumerous heterogeneous $P$. australis surface adsorption sites. This was also supported by the results of the kinetic study for COD, BOD, TSS and TDS removal, which were obtained following the pseudo secondorder model. This model, used to clarify the probability of overall adsorption properties, was suited to the chemical adsorption mechanism. Finally, IRSM was employed for modeling and optimizing COD, BOD, TSS and TDS biosorption on $P$. australis. The nature of water after treatment was observed to be appropriate for water system utilization and for coordinated release into streams.

\section{Conflicts of interest}

The authors have no conflict of interest.

\section{Acknowledgements}

The authors express gratitude to the staff of the Environmental Engineering Laboratory, Faculty of Engineering, Zagazig University. 


\section{References}

1 M. A. Armour, Hazardous Laboratory Chemicals Disposal Guide. CRC Press, Boca Raton, 1991.

2 F. Naseeruteen, A. N. Shahirah, F. M. S. Bukhari, W. N. Saime and F. M. Shimal, Int. J. Biol. Macromol., 2017, DOI: 10.1016/ j.ijbiomac.2017.09.111.

3 R. Devi and R. P. Dahiya, Water, Air, Soil Pollut., 2006, 174, 33-46.

4 S. J. Kulkarni, International Journal of Science, Engineering and Technology Research, 2016, 41-52.

5 S. J. Kulkarni, International Journal of Science, Engineering and Technology Research, 2013, 2, 2278-7798.

6 Y. Cheng, C. Yang, H. He, G. Zeng, K. Zhao and Z. Yan, J. Environ. Eng., 2015, C4015001-C4015007.

7 H. J. He, Z. H. Xiang, X. J. Chen, H. Chen, H. Huang, M. Wen and C. P. Yan, Int. J. Environ. Sci. Technol., 2018, 15, 14911500.

8 N. M. Nor, L. L. Chung, L. K. Teong and A. R. Mohamed, J. Environ. Chem. Eng., 2013, 1, 658-666.

9 A. M. El-Wakil, W. M. Abou El-Maaty and F. S. Awad, J. Anal. Bioanal. Tech., 2014, 5, 1-14.

10 M. Han, J. Qu and Q. Guo, Procedia Eng., 2015, 102, 450-457. 11 I. Ozdemir, M. Sahin, R. Orhan and M. Erdem, Fuel Process. Technol., 2014, 125, 200-206.

12 H. Liu, P. Dai, J. Zhang, C. Zhang, N. Bao, C. Cheng and L. Ren, Chem. Eng. J., 2013, 228, 425-434.

13 M. A. Nahil and P. T. Williams, Biomass Bioenergy, 2012, 37, 142-149.

14 J. M. Salman, V. O. Njoku and B. H. Hameed, Chem. Eng. J., 2011, 174, 41-48.

15 W. Li, L. Zhang, J. Peng, N. Li and X. Zhu, Ind. Crops Prod., 2008, 27, 341-347.

16 R. C. de Andrade, C. F. de Almeida, P. H. Suegama, E. J. de Arruda, P. A. Arroyo and C. T. deCarvalho, Environmental Technology \& Innovation, 2015, 3, 28-34.

17 M. A. Chayid and M. J. Ahmed, J. Environ. Chem. Eng., 2015, 3, 1592-1601.

18 M. J. Ahmed, J. Taiwan Inst. Chem. Eng., 2016a, 63, 336-343.

19 J. Ma, Y. Liu, O. Ali, Y. Wei, S. Zhang, Y. Zhang, T. Cai, C. Liu and S. Luo, J. Hazard. Mater., 2017, 17, 863-874.

20 Y. Huang, C. Yang, Z. Sun, G. Zeng and H. He, RSC Adv., 2015, 5, 11475-11484.

21 B. K. Gökben, U. M. Aysegül and T. Ilhami, Ecol. Eng., 2016, 86, 85-94.

22 J. Srivastava, S. J. S. Kalra and R. Naraian, Appl. Water Sci., 2014, 4, 193-202.

23 A. EL Shahawy and G. Heikal, Ecol. Eng., 2018, 122, 207-218.

24 M. Brink and E. G. Achigan-Dako, Plant Resources of Tropical Africa 16, Fibers, PROTA Foundation/CTA, Wageningen, Netherlands, 2012.

25 J. F. Köbbing, N. Thevs and S. Zerbe, Sciences in Cold and Arid Regions, 2016, 8, 35-47.

26 I. Langmuir, J. Am. Chem. Soc., 1918, 40, 1361-1368.

27 H. Freundlich, J. Phys. Chem., 1906, 57, 384-410.

28 Y. S. Ho and G. McKay, Process Biochem., 1999, 34, 451-465.
29 M. G. Alalm, M. Nasr and S. Ookawara, Sep. Purif. Technol., 2016, 169, 137-150.

30 L. H. Mohmoud, Engineering Technology Journal, 2012, 30, 344-353.

31 M. T. Bankole, A. S. Abdulkareem, J. A. Tijani, S. S. Ochigboa, A. S. Afolabi and D. W. Roos, Water Resources and Industry, 2017, 18, 33-50.

32 G. Mariani, PhD thesis, ALMA MATER Studiourm, University of Bologna-Faculty of Engineering, Department of Electrical Engineering, 2010.

33 M. Kallel, C. Belaid, T. Mechichi, M. Ksibi and B. Elleuch, Chem. Eng. J., 2009, 150(2), 391-395.

34 N. Saranya, E. Nakkeeran, S. Shrihari and N. Selvaraju, Arabian J. Sci. Eng., 2017, 42, 1545-1557.

35 A. J. Maher, D. Hiba, Z. Nareman and E. Nadia, International Journal of Thermal \& Environmental Engineering, 2017, 15, 5761.

36 A. L. Ahmad, S. Sumathi and B. H. Hameed, Chem. Eng. J., 2005, 108, 179-185.

37 A. Bhavna, V. Ajay and M. Pathik, Arch. Appl. Sci. Res., 2011, 3, 327-341.

38 Q. Xie, Y. Li, Z. Lv, H. Zhou, X. Yang, J. Chen and H. Guo, Sci. Rep., 2017, 7, 3316-3329, DOI: 10.1038/s41598-017-03526.

39 M. Delkash, B. E. Bakhshayesh and H. Kazemian, Microporous Mesoporous Mater., 2015, 214, 224-241.

40 K. Kaur, S. Mor and K. Ravindra, J. Colloid Interface Sci., 2016, 469, 338-343.

41 I. Anastopoulos, A. Bhatnagar, B. H. Hameed, Y. Sik Ok and M. Omirou, J. Mol. Liq., 2017, 240, 179-188.

42 M. Ligaray, C. M. Futalan, M. Daniel and M. Weiwan, J. Cleaner Prod., 2018, 175, 145-154.

43 A. Halim, M. N. Z. Abidin, N. Awang, A. Ithnin, M. S. Othman and M. I. Wahab, Journal of Urban and Environmental Engineering, 2011, 5, 24-31, DOI: 10.4090/ juee.2011.v5n1.024031.

44 R. Devi, V. Singh and A. Kumar, Bioresour. Technol., 2008, 99, 1853-1860.

45 D. Mohan, K. P. Singh and V. K. Singh, J. Hazard. Mater., 2008, 152, 1045-1053.

46 A. K. Parande, A. Sivashanmugam, H. Beulah and N. Palaniswamy, J. Hazard. Mater., 2009, 168, 800-805.

47 A. A. Ahmad and B. H. Hameed, J. Hazard. Mater., 2009, 172, 1538-1543.

48 D. Kalderis, D. Koutoulakis, P. Paraskeva, E. Diamadopoulos, E. Otal, J. O. Valle and C. FernándezPereira, Chem. Eng. J., 2008, 144, 42-50.

49 K. Tong, Y. Zhang, D. Fu, X. Meng, Q. An and P. K. Chu, Colloids Surf., A, 2014, 447, 120-130.

50 W. Xu, Q. Zhao, R. Wang, Z. Jiang, Z. Zhang, X. Gao and Z. Ye, Vacuum, 2017, 141, 307-315.

51 M. Zhang, Q. Zhao and Z. Ye, J. Environ. Sci., 2011, 23(12), 1962-1969.

52 Y. Zhang, Z. Jiang, Q. Zhao, Z. Zhang, H. Su, X. Gao and Z. Ye, Water Sci. Technol., 2016, 1313-1319, DOI: 10.2166/ wst.2015.581. 
53 C. A. Gallo, G. M. Silva, M. del, G. A. Muñoz, F. X. Arboleda and S. D. Almeida, J. Environ. Chem. Eng., 2017, 5(4), 40414050 .

54 M. A. Kameli, M. Chorom, N. Jaafarzadeh and H. Janadeleh, Global J. Environ. Sci. Manage., 2017, 3, 197-206, DOI: 10.22034/gjesm.03.02.008.

55 M. M. Lakdawala and Y. S. Patel, Arch. Appl. Sci. Res., 2012, 4, 852-857.
56 K. Murali, P. L. Karuppiah, M. Nithish, S. S. Kumar and V. S. Raja, International Journal of Scientific and Research Publications, 2013, 3, 146-153.

57 W. Pitakpoolsil and M. Hunsom M, J. Taiwan Inst. Chem. Eng., 2013, 44(6), 963-971.

58 N. Phawinee, K. Kittiwut and S. Wanwisa, J. Environ. Chem. Eng., 2017, 6(1), 794-802. 